\title{
La crisis económica internacional y sus repercusiones en España y en su población inmigrante
}

\section{The impact of the international economic crisis in the Spanish immigration policy}

\author{
Juan A. Cebrián, María Isabel Bodega, \\ María Asunción Martín-Lou y Fabián Guajardo*
}

\section{INTRODUCCIÓN}

Precedido por un flujo notable de inmigrantes en la últimas dos décadas del siglo xx, el incremento de la población extranjera residente en España a partir del año 2000 ha sido extraordinario. En 1999 la cifra de residentes extranjeros en España era de 750.000 personas (el 1,86\% del total de la población). Diez años más tarde los extranjeros residentes en España son más de 5,5 millones (el 12\% de la población total). Las tasas de crecimiento anuales han sido comprensiblemente más importantes en los años de las regularizaciones masivas, que culminaron en la del 2005. En ese año el número de residentes extranjeros oficiales aumentó casi un 50\%. España ha recibido durante los últimos años la tercera parte de los inmigrantes que recibía la OCDE, siendo el segundo país de inmigración en términos absolutos (detrás de Estados Unidos) y el primero en términos relativos. La mayoría de los residentes extranjeros en España son inmigrantes laborales, aunque el cupo de residentes europeos jubilados es notable.

* Juan A. Cebrián (juanantonio.cebrian@cchs.csic.es), María Isabel Bodega (isabel.bodega@cchs.csic.es), María Asunción Martín-Lou (mariasun.martin@cchs.csic.es) y Fabián Guajardo (fabian.guajardo@cchs.csic.es). Instituto de Economía, Geografía y Demografía, Centro de Ciencias Humanas y Sociales, CSIC, Madrid. 
Aproximadamente, hay 3,4 millones de inmigrantes laborales en España y 1,1 millones de jubilados europeos (INE, 2009). En este artículo presentamos los cambios recientes que se han verificado en los flujos de inmigrantes laborales, a raíz de la recesión económica mundial en la que nos encontramos. Naturalmente, las llegadas de inmigrantes laborales a España se han reducido drásticamente, por el descenso de la demanda de mano de obra en nuestro mercado de trabajo, seriamente amenazado por el desempleo de naturales e inmigrantes.

La inesperada - hasta cierto punto- contracción de la actividad económica ha provocado un cambio de orientación en la política migratoria del estado español, cuya mayor preocupación, hasta ahora, había sido la normalización de un voluminoso flujo de inmigrantes en continua progresión. Así, la nueva política migratoria española resulta disuasoria para los que están fuera, claramente integradora de los que están dentro, abierta a la repatriación de los que así lo deseen y, experimentalmente, descentralizada en todos sus aspectos.

Analizaremos la crisis en la economía española y, como consecuencia, las repercusiones en su inmigración.

\section{EL FACTOR DEMOGRÁFICO}

La llegada de inmigrantes ha resultado esencial en el proceso de incremento de la población residente en España y de sus consecuencias en el mercado laboral español ${ }^{1}$. A principios del año 2000 la población residente en España era de 40.200.000, aproximadamente. Diez años más tarde residen en España 46.750.000 individuos, lo que significa un inusitado crecimiento poblacional del $16,3 \%$. La incapacidad de la mano de obra española para satisfacer la demanda de trabajo se manifestó, de manera definitiva, en los primeros años del nuevo siglo. Entre los años 2001 y 2005 los españoles ocuparon el $47,3 \%$ de los nuevos empleos, mientras que los inmigrantes accedían al $52,7 \%$ restante. En el 2006, sin la aportación de 450.000 nuevos ocupados inmigrantes, cerca del $60 \%$ de los 767.000 nuevos puestos de trabajo creados en aquel año, hubiesen quedado sin cubrir.

\footnotetext{
${ }^{1}$ En el año 2001 había 18 millones de activos en España. El año 2009 había 22,97 millones: un aumento absoluto de 5 millones en sólo ocho años. (INE, Explotación Estadística de la Encuesta de Población Activa, www.ine.es).
} 
FIGURA 1

TOTAL DE POBLACION EXTRANJERA EN ESPAÑA (2000-2009)

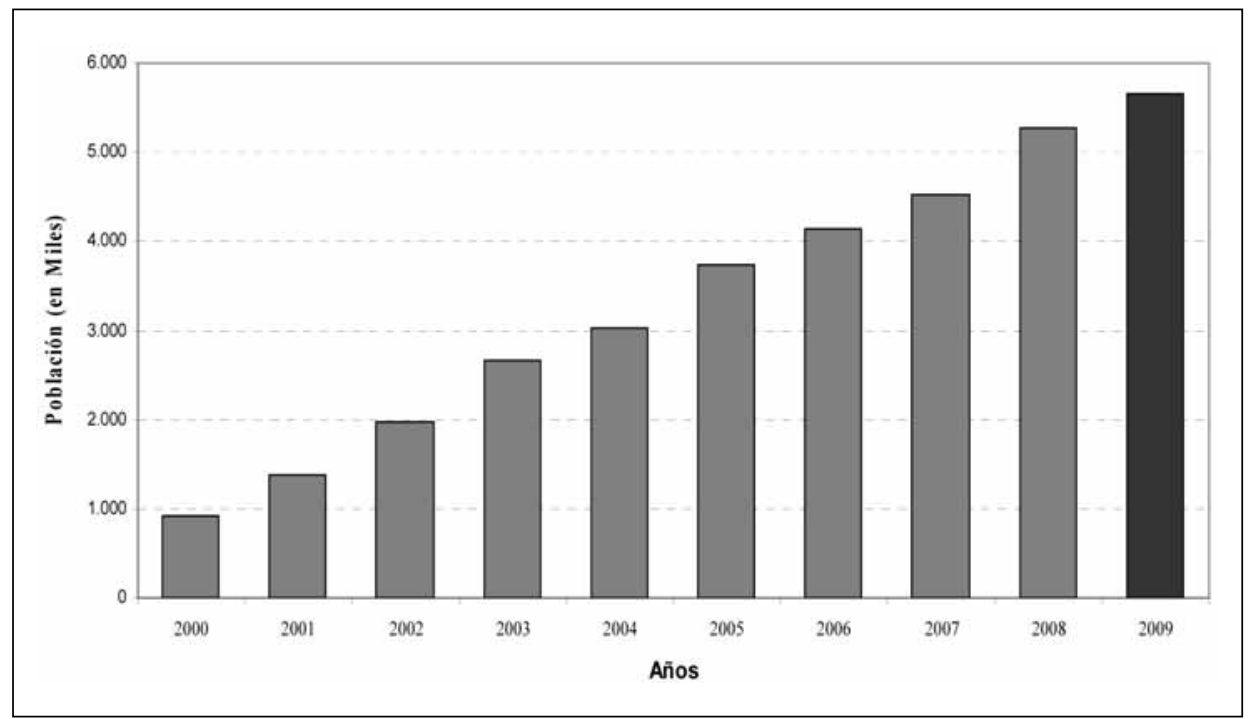

Fuente: Cifras de Población del INE. www.ine.es Elaboración propia.

La llegada de este considerable número de inmigrantes a España es el resultado combinado de condiciones técnicas (como el desarrollo de los medios de transporte y de las telecomunicaciones), socioeconómicas (como el progresivo distanciamiento de los países desarrollados de los países en desarrollo) y político institucionales (como el desplome del bloque soviético, o la consolidación y posterior engrandecimiento de la Unión Europea).

El crecimiento económico ha requerido la aportación de los trabajadores inmigrantes, fundamentalmente en sectores que necesitan una cantidad muy elevada de mano de obra. Sin esa contribución, la sociedad española hubiese tenido que renunciar al crecimiento, al menos en las tasas tan elevadas que se registraron año tras año, y, consiguientemente, a sus consecuencias sociales más beneficiosas. La contribución de la inmigración ha sido, por tanto, indispensable para el desarrollo económico en España desde los años noventa hasta la crisis actual.

La inmigración reciente ha abierto un nuevo capítulo de la historia de España, no sólo por haber sustentado un crecimiento económico sin precedentes, sino también por haber modificado la estructura y la dinámica demo- 
gráfica española, rejuveneciendo su población y cambiando la tendencia a la baja de su fecundidad. Además, la inmigración ha supuesto un cambio sociocultural que se caracteriza, ante todo, por un mayor pluralismo. No se puede imaginar el futuro de España sin la presencia y las aportaciones de estos nuevos «ciudadanos».

Aunque circunstancialmente, debido a la falta real de puestos de trabajo que la crisis económica ha desencadenado, se limiten las entradas prolongadas de residentes de terceros países con fines laborales, España no puede adoptar una política migratoria de puertas cerradas. La inmigración seguirá siendo necesaria para nuestro país; su contribución continuará supliendo la falta de candidatos nacionales o residentes extranjeros para un número significativo de ocupaciones que demandarán los empleadores y cuyo volumen estará determinado por los escenarios económicos que se vayan consolidando a lo largo de los próximos años. Si no se contara con la llegada de personas de otros países para trabajar en España, el envejecimiento poblacional acabaría reduciendo su potencial de crecimiento demográfico y comprometería gravemente su capacidad económica. Ahora bien, es esperable que en el futuro la inmigración se produzca en proporciones más modestas a las registradas en la última década, superando la fase de impacto y modificando el perfil socioprofesional del inmigrante, de manera que exista un mayor equilibrio en sus cualificaciones.

\section{POLÍTICAS MIGRATORIAS ESPAÑOLAS ANTERIORES A LA CRISIS}

España ha recibido un contingente inmigratorio irregular notable, de manera semejante a otros países de la Unión Europea: Italia y Grecia, fundamentalmente. Lo mismo ocurre al otro lado del Atlántico donde, Estados Unidos también se ha visto afectado por una inmigración irregular muy importante. En todos los casos citados se comprueba que, esta inmigración irregular es un vector que, cruzando la frontera sur del norte, apunta al mundo desarrollado. Los inmigrantes irregulares han tenido siempre que asumir riesgos importantes, especialmente a partir del momento en que, por la importancia de su número en los países de llegada, se produce una reacción sociopolítica que desemboca en una normativa de control de fronteras, o, usando la terminología más reciente, de ordenación de las migraciones internacionales.

En el caso español, en el período 2000-2009, la migración irregular se diferencia de la que ha tenido lugar en los otros países antes mencionados (Italia, Grecia y Estados Unidos). Nos referimos al hecho de que los inmigrantes irre- 
gulares en España no proceden solamente de países en desarrollo más cercanos. En Italia y Grecia los inmigrantes irregulares más numerosos proceden de los Balcanes, del norte de África y de Oriente Medio, cruzando los puentes naturales de Pantelleria-Lampedusa-Malta-Sicilia y de Turquía. En Estados Unidos, la migración irregular es ante todo mexicana. España también recibe inmigrantes irregulares de su entorno, de Marruecos fundamentalmente. Los marroquíes irregulares cruzan el Estrecho de Gibraltar o el Mar de Alborán en pateras para llegar a la Península Ibérica; o surcan el Atlántico occidental en cayucos parra llegar a las Islas Canarias². Poner un pie en las Canarias significa haber desembarcado en la Unión Europea ${ }^{3}$.

En el boom inmigratorio español de estos años, además, ha intervenido también un contingente muy importante de oriundos de países más lejanos, que podemos clasificar en dos flujos principales, con un volumen semejante o superior al que procede directa o indirectamente de África. En primer lugar, muy destacados, se encuentran los inmigrantes latinoamericanos, quienes utilizando, como puerta de entrada, el aeropuerto de Madrid-Barajas con visas de turista o estudiante, al cabo de tres meses en territorio español, se convierten en inmigrantes sin papeles. En segundo lugar, debe mencionarse la inmigración de países de Europa del Este que, sorteando las dos líneas de contención de la Unión Europea ${ }^{4}$, llega a España cruzando la frontera franco española en autobuses de líneas regulares. Conforme la UE ha ido extendiéndose hacia el Este en los últimos diez años, la procedencia de los inmigrantes ha variado (polacos en la década 1990-1999; rumanos y búlgaros a partir del cambio de siglo).

La importancia de la inmigración irregular en todos estos países ha condicionado seriamente las políticas migratorias, como veremos más adelante. La concesión de amnistías, regularizaciones; normalizaciones a los inmigrantes

${ }^{2}$ Los años 2006 y 2007 presenciaron una auténtica avalancha de cayucos, que sólo pudo ser frenada por la cooperación de toda la UE en operaciones navales de vigilancia, intercepción y rescate. Paralelamente, se instrumentaron numerosas acciones diplomáticas, que ofrecían a los gobiernos de los países de origen de los tripulantes de los cayucos fondos para el desarrollo, a cambio de autocontrol migratorio.

3 Todos los países mencionados, España incluida, reciben también una inmigración indirecta de países más lejanos, pero que penetra en ellos por las puertas arriba mencionadas: subsaharianos en Italia y en Grecia, naturales de Oriente Medio, Irán, Pakistán, etc. en Grecia, centroamericanos y sudamericanos en Estados Unidos, subsaharianos en España, etc.

${ }^{4}$ Las dos líneas a que hacemos referencia son, respectivamente, la frontera Este de los últimos doce países de la UE y la frontera Este de la UE anterior a la incorporación de éstos, que temporalmente sigue operativa como control de entradas. 
FIGURA 2

CRECIMIENTO DE LOS PRINCIPALES COLECTIVOS INMIGRANTES EN ESPAÑA (2000-2009)

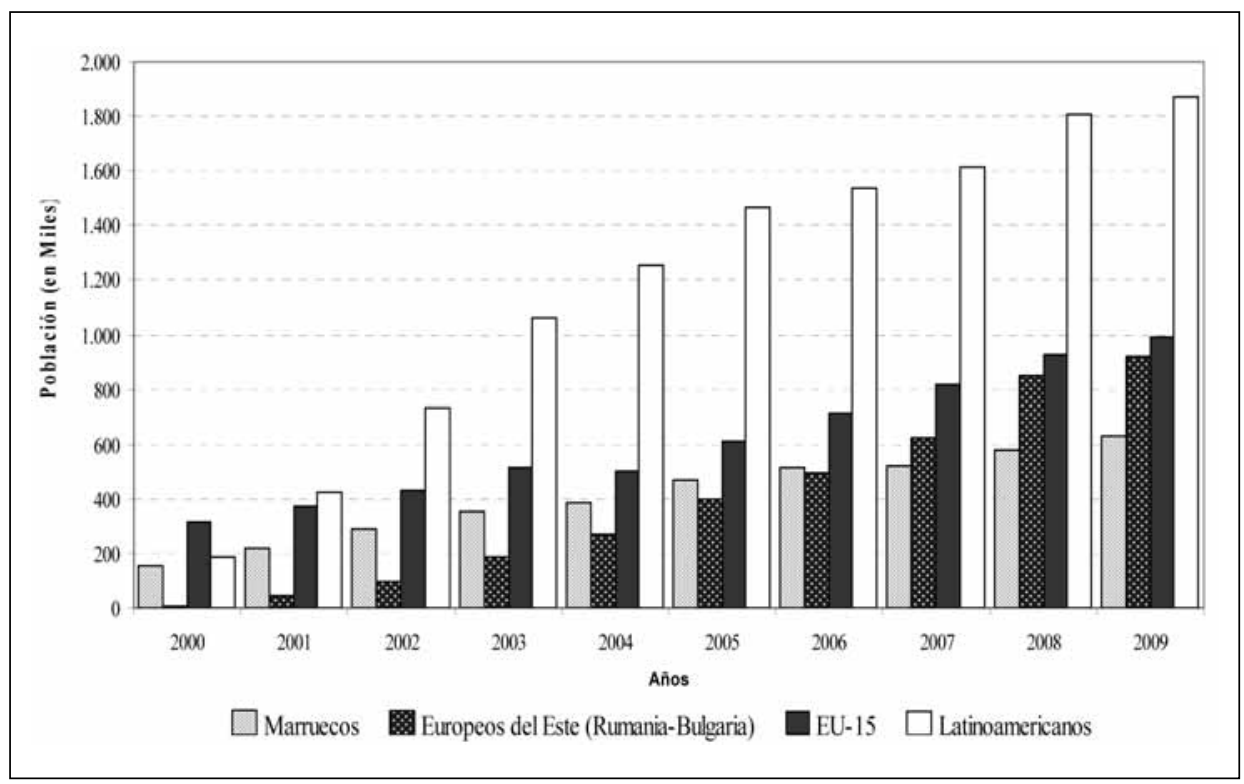

Fuente: Cifras de Población del INE. www.ine.es Elaboración propia.

irregulares ha sido, sin duda, el procedimiento más utilizado para incorporar a grandes contingentes de residentes extranjeros, sin papeles. Como muestra de la importancia que la política de amnistías tiene, podemos mencionar que en España, solamente en un año, en el 2005, se normalizaron/regularizaron 500.136 inmigrantes. Desde entonces, en España no ha vuelto a haber ninguna otra normalización masiva.

En España, independientemente de qué partido gobierne, las políticas migratorias se han desarrollado alrededor de un consenso generalizado, basado en la aceptación de numerosos inmigrantes, demandados por las crecientes actividades productivas de los sectores económicos. Aunque las diferentes leyes de extranjería hayan sido objeto de numerosas enmiendas, e, incluso, se haya puesto en duda su perfecta constitucionalidad, en el período de referencia (2000-2009), ha predominado el continuismo, no habiendo cambios de dirección bruscos en la evolución de las políticas migratorias formuladas. 
En términos generales, se puede afirmar que la política inmigratoria española ha pasado por cinco momentos fundamentales. En el primer momento, la política migratoria se formula casi exclusivamente como un problema de control de cruces irregulares de la frontera española. Es la reacción de un país que nunca había experimentado un influjo importante de trabajadores y que dudaba de que se necesitara mano de obra extranjera para llevar a buen término las nuevas demandas económicas, nacionales e internacionales. En esos momentos el inmigrante laboral resultaba un elemento desconocido, útil quizás, pero extraño y, por ello, sometido a una vigilancia o control impropios de los residentes en un país democrático. Es un momento difícil, porque la legislación existente es reducida y no facilita la regularización de los trabajadores extranjeros.

Una vez superada esta circunstancia y reconocida socialmente la necesaria presencia de los trabajadores inmigrantes en España, la política migratoria entra en una segunda fase, cuyo imperativo consiste en normalizar a la población inmigrante residente en España. Es el momento de las amnistías o regularizaciones masivas $(1996,2000,2005)$ y, aunque tenga menor repercusión en el volumen total de trabajadores inmigrantes, del desarrollo de un aparato burocrático-legal que acompañe a los inmigrantes en su inserción progresiva en el mercado laboral regular: leyes orgánicas 4/2000, 8/2000 y 14/2003 y sus correspondientes reglamentos de aplicación. Es en esta fase donde se plantean, o replantean, los permisos de residencia y trabajo, las cuotas o contingentes, las relaciones de puestos de trabajo de difícil cobertura, los tratados bilaterales que faciliten los trasvases de población entre España y otros países de interés especial ${ }^{5}$, la incorporación de directivas comunitarias en materia migratoria, los programas de contratación en origen, las políticas de visados, etc.

España concede tres tipos principales de visados. El visado de turista se concede para estancias de tres meses máximo, con suficiente liberalidad. El visado de estudiante tiene una duración que depende del tipo de estudios: debe ser renovado anualmente y exige una justificación meticulosa del cumplimiento de las actividades académicas que han motivado la concesión del permiso. Y el visado o permiso de residencia, que es el que se relaciona con el estatus de los trabajadores extranjeros. El permiso de residencia puede ser temporal o permanente y sólo se concede a aquellas personas que a) de-

\footnotetext{
${ }^{5}$ Entre otros, España tiene firmados convenios bilaterales de ordenación de flujos migratorios con Colombia, Ecuador, Marruecos (2001), con Polonia, República Dominicana, Rumania (2002), con Bulgaria (2003), con Mauritania (2007), con Cabo Verde (2008), etc.
} 
muestran tener previamente los medios económicos para mantenerse mientras residan en España (mera residencia) b) presentan un contrato de trabajo en España (trabajo) c) se identifican como familiares de primer grado de un residente extranjero en España (reunificación familiar). El permiso de residencia permanente se concede a las personas que lo solicitan, después de cinco años de residencia legal continuada. El permiso de residencia permanente está regulado por la directiva 2003/109 de la Unión Europea y lleva consigo, entre otros, la adquisición de los mismos derechos laborales que los españoles. En el cuadrol se detallan los visados, no de turista, concedidos en España en el año 2008 (280.295), por tipo de visado y continente de origen del solicitante. En ese año las solicitudes de asilo fueron simplemente 6.946 .

CUADRO 1

PERMISOS/VISADOS DE RESIDENCIA EN ESPAÑA: 2008.

\begin{tabular}{lccrrr}
\hline $\begin{array}{c}\text { Lugar } \\
\text { de origen }\end{array}$ & Total & $\begin{array}{c}\text { Mera } \\
\text { residencia }\end{array}$ & Trabajo & $\begin{array}{c}\text { Reunificación } \\
\text { familiar }\end{array}$ & Estudiante \\
\hline EU & 19.318 & & $99,7 \%$ & $0,2 \%$ & $0,1 \%$ \\
Resto de Europa & 11.115 & $1,4 \%$ & $42,9 \%$ & $39,5 \%$ & $16,2 \%$ \\
África & 64.466 & $0,7 \%$ & $46,4 \%$ & $49,9 \%$ & $3,0 \%$ \\
Norteamérica & 16.418 & $5,4 \%$ & $5,3 \%$ & $0,1 \%$ & $89,3 \%$ \\
Latinoamérica & 140.958 & $1,0 \%$ & $50,3 \%$ & $34,3 \%$ & $14,5 \%$ \\
Asia & 27.981 & $2,5 \%$ & $34,1 \%$ & $50,5 \%$ & $12,8 \%$ \\
\hline Total & 280.296 & & & \\
\hline
\end{tabular}

Fuente: Anuario Estadístico de Inmigración. MTIN. Elaboración propia.

En una tercera fase, la política migratoria de España favorece la integración de los residentes extranjeros que tengan un proyecto migratorio a medio o largo plazo. Esta línea de actuación ha contado desde el primer momento con la colaboración de los gobiernos autonómicos y locales, del sector empresarial, así como de numerosísimas asociaciones asistenciales y de la sociedad civil.

La defensa de los derechos civiles de los inmigrantes aparece ya en las primeras leyes de extranjería españolas. No obstante lo cual, especialmente en el caso de los derechos que no están relacionados con la supervivencia física o 
moral de las personas, la preocupación proactiva por estos temas aparece en una cuarta fase.

En una quinta fase se plantea la cuestión de la descentralización autonómica de la política migratoria del Estado Español. En la ley orgánica 2/2009 se aborda este aspecto, que sigue todavía sujeto a intensa controversia en las cámaras legislativas. La oposición a la descentralización absoluta de la gestión migratoria radica en la salvaguarda del principio de soberanía nacional.

Estas cinco fases no son exclusivas, más bien se solapan en el tiempo. Puede perfectamente ocurrir que una fase anterior no concluya antes que otras posteriores, o que quede abierta indefinidamente. El orden que hemos enunciado es el de aparición en el marco de las políticas inmigratorias españolas actuales.

\section{LA CRISIS ECONÓMICA EN ESPAÑA Y SU IMPACTO EN LA INMIGRACIÓN}

En el año 2008 se manifiesta en España la anunciada recesión de la economía occidental, acompañada de una contracción severa de la demanda de trabajo. Este fenómeno repercute indudablemente en las políticas migratorias que, hasta el momento, habían sido concebidas para acomodar a una mano de obra necesaria en un largo período de crecimiento económico ${ }^{6}$. En escasos meses, el paro laboral ha alcanzado dimensiones históricas (ver cuadro 2, en el se detalla la evolución de las cifras absolutas de paro en España, por sexos, entre 2005 y 2009), afectando de manera diversa a inmigrantes y nacionales. La disminución de la calidad de vida de la población inmigrante en los dos últimos años se ha manifestado de muy diferentes maneras, entre ellas, el descenso de la remesas a sus países de origen: un 13\% en el año 2009.

Pese a que se vislumbran los primeros rasgos de recuperación macroeconómica, como se aprecia en la figura 3 (que representa las tasas de crecimiento del PIB en España) a partir del segundo trimestre de 2009, la destrucción de puestos de trabajo continúa, y sigue siendo más acusada que en otros países europeos.

\footnotetext{
${ }^{6}$ A este respecto ver: Aja, E. y Arango, J. en «La inmigración en tiempos de crisis. Anuario de la inmigración en España», CIDOB, 2010. 
CUADRO 2

PARADOS SEGÚN SEXO PERÍODO 2005-2009

(CIFRAS POR TRIMESTRE)

\begin{tabular}{llrl}
\hline $\begin{array}{c}\text { En miles de } \\
\text { personas }\end{array}$ & $\begin{array}{c}\text { Ambos } \\
\text { sexos }\end{array}$ & Varones & Mujeres \\
\hline 2005 TI & 2.099 & 940,9 & $1.158,1$ \\
2005 TII & $1.944,7$ & 890,1 & $1.054,6$ \\
2005 TIII & 1.765 & 799,2 & 965,8 \\
2005 TIV & $1.841,3$ & 821,2 & $1.020,1$ \\
2006 TI & $1.935,8$ & 846,4 & $1.089,4$ \\
2006 TII & 1.837 & 795,5 & $1.041,5$ \\
2006 TIII & 1.765 & 760,3 & $1.004,8$ \\
2006 TIV & $1.810,6$ & 763,8 & $1.046,9$ \\
2007 TI & $1.856,1$ & 800,1 & 1.056 \\
2007 TII & 1.760 & 780,6 & 979,3 \\
2007 TIII & $1.791,9$ & 800,9 & 991 \\
2007 TIV & $1.927,6$ & 879,2 & $1.048,3$ \\
2008 TI & $2.174,2$ & $1.018,6$ & $1.155,6$ \\
2008 TII & $2.381,5$ & $1.182,9$ & $1.198,6$ \\
2008 TIII & $2.598,8$ & $1.353,6$ & $1.245,2$ \\
2008 TIV & $3.207,9$ & $1.688,8$ & 1.519 \\
2009 TI & $4.010,7$ & $2.195,8$ & $1.814,9$ \\
2009 TII & $4.137,5$ & $2.289,1$ & $1.848,4$ \\
2009 TIII & $4.123,3$ & $2.290,9$ & $1.832,5$ \\
2009 TIV & $4.326,5$ & $2.392,5$ & 1.934 \\
\hline
\end{tabular}

Fuente: Encuesta de Población Activa, INE www.ine.es. Elaboración propia.

En la figura 4 se representa la evolución las tasas de paro en España en la primera década del siglo XXI, junto con las de siete países europeos y la tasa media de los países del EU-15. Hay países (Francia y Alemania, por ejemplo), que sufren una contracción económica similar a la española pero que han tenido un incremento menor de población activa en el pasado reciente y un sector de la construcción menos explosivo, por ello tienen tasas de paro más razonables. Pero también hay países en la UE con fluctuaciones de mano de obra y de volumen de negocio inmobiliario próximas a las de España (Irlanda o el Reino Unido, por ejemplo), y aún así tienen niveles de paro menos dramáticos.

Este comportamiento del mercado de trabajo español sugiere que sus mecanismos de ajuste frente a las vicisitudes de la economía global no están fun- 
FIGURA 3

TASA (INTERANUAL E INTERTRIMESTRAL) DE CRECIMIENTO DEL PIB DE ESPANA (2005-2009)

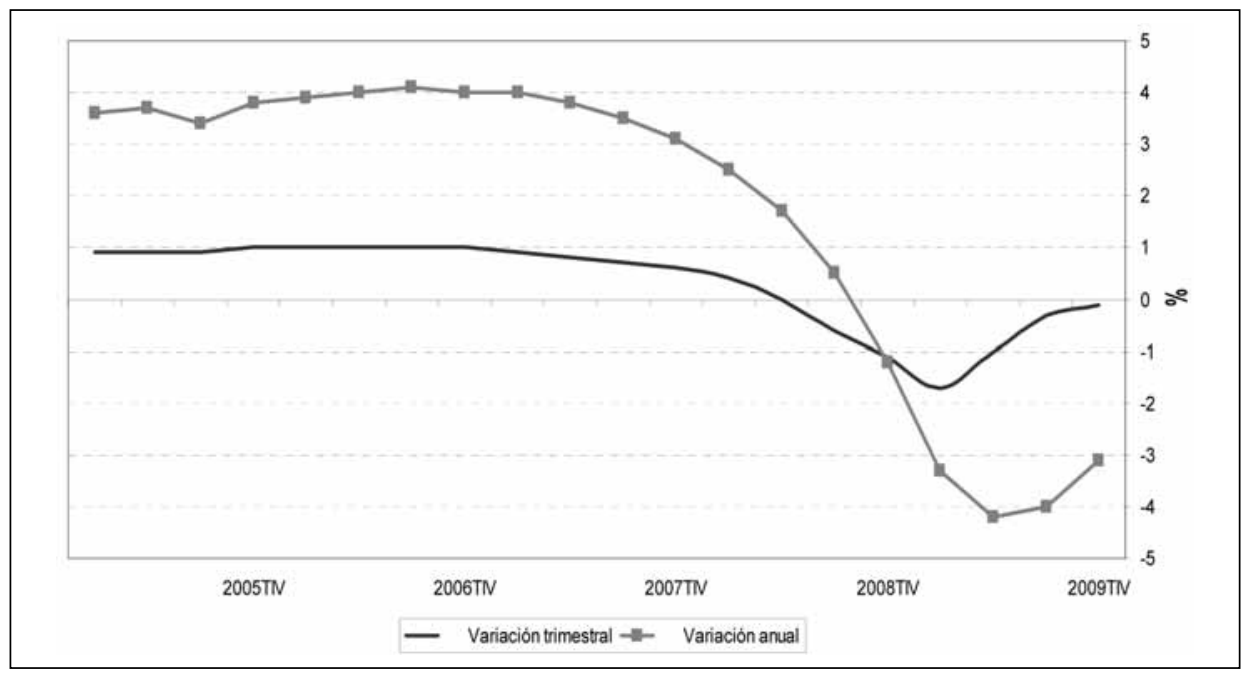

Fuente: Contabilidad Nacional Trimestral de España, INE. www.ine.es. Elaboración propia.

FIGURA 4

COMPARACIÓN DE LAS TASAS DE DESEMPLEO EN EUROPA. SERIE 2000 AL 2009 EN LOS EU-15 Y SELECCIÓN DE PAÍSES

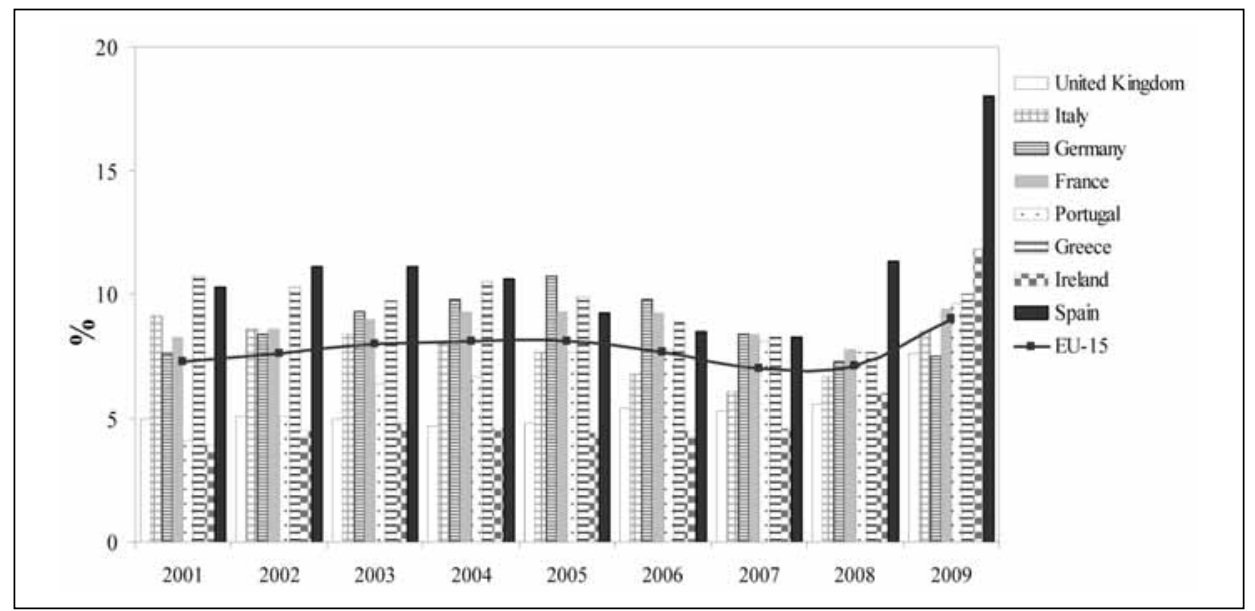

Fuente: Eurostat, http://epp.eurostat.ec.europa.eu. Elaboración propia. 
cionando adecuadamente. Deficiencias como la temporalidad, la precariedad, el bajo crecimiento de la productividad y la elevada variabilidad del empleo, que es una de las características más peculiares del comportamiento cíclico de la economía española, resultan, en este momento, especialmente difíciles de corregir 7 .

El cuadro 3 contiene algunos indicadores cíclicos del PIB y del empleo en los cuatro grandes países de la zona Euro, para el período IT 1992-IIIT 2008. Como se puede apreciar, la volatilidad del empleo relativa a la del PIB (medida por la ratio de desviaciones estándar) es mucho mayor en España que en el resto de países grandes de la zona Euro. De hecho, España es el único país de los cuatro donde el empleo fluctúa más que el PIB, mientras que en Alemania y Francia se observa lo contrario y en Italia ambas variables tienen aproximadamente la misma volatilidad. Asimismo, la correlación entre empleo y PIB es también más fuerte en España que en el resto de países.

CUADRO 3

VOLATILIDAD DEL EMPLEO Y DEL PIB Y SU CORRELACIÓN 1992-2008.

\begin{tabular}{lcccc}
\hline \multicolumn{1}{c}{ VOLATILIDAD (\%) } & Alemania & Francia & Italia & España \\
\hline Empleo (1) & 1,0 & 1,0 & 1,4 & 2.3 \\
PIB (2) & 1,4 & 1,2 & 1,4 & 1,8 \\
Ratio (1)/(2) & 0,8 & 0,8 & 1,0 & 1,3 \\
\hline CORRELACIÓN & 0,5 & 0,7 & 0,3 & 0,8 \\
PIB-Empleo & & & & \\
\hline
\end{tabular}

Fuente: Banco Central Europeo. Series trimestrales del PIB y del empleo en tasas de crecimiento interanuales. Elaboración propia.

Mientras la tasa de desempleo de los españoles se encuentra ya en el $16,8 \%$, la de la población inmigrante (trabajadores extranjeros) alcanza la cifra insostenible del 29,7\%. En una situación como la presente, la política migratoria española ha girado hacia objetivos más conservadores. Como veremos más adelante, sin congelar definitivamente la inmigración laboral, ni

\footnotetext{
${ }^{7}$ Sobre la crisis en mercado del trabajo español y la relación con la inmigración, ver: Oliver, J. en «La inmigración en tiempos de crisis. Anuario de la inmigración en España», CIDOB, 2010 .
}

Estudios Geográficos, Vol. LXXI, 268, pp. 67-101, enero-junio 2010

ISSN: 0014-1496, eISSN: 1988-8546, doi: 10.3989/estgeogr.0505 
suprimir, por motivos humanitarios evidentes, los procedimientos de reagrupación familiar, se pretende evitar la llegada indiscriminada de trabajadores. Se prima la inmigración cualificada y la cobertura de los puestos de trabajo que el mercado laboral español no puede, de hecho, satisfacer. Se facilita a los inmigrantes que lo soliciten el retorno a sus países y se extreman las medidas de protección de los derechos adquiridos por los extranjeros residentes en España y las buenas prácticas de su integración. (figuras 5 y 6)

\section{FIGURA 5}

COMPARACIÓN DE LA POBLACIÓN Y LA TASA DE DESEMPLEO ENTRE NACIONALES Y EXTRANJEROS EN ESPAÑA (TRIMESTRES 2005 AL 2009)

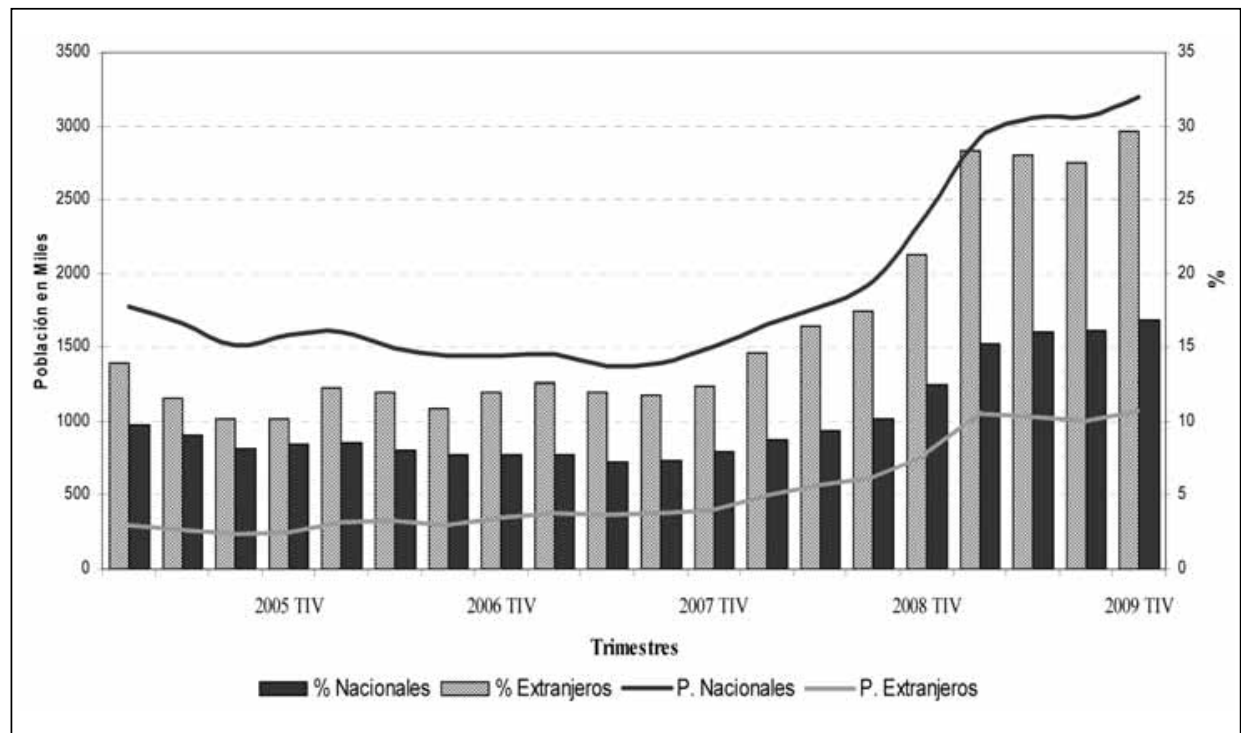

Fuente: Encuesta de Población Activa, INE www.ine.es. Elaboración propia.

La tasa de paro de la población extranjera previa a la crisis — por ejemplo, en el año 2005- era de cerca del 14\%, unas 300.000 personas. La de los nacionales españoles era inferior en unos 4 puntos porcentuales. Esta diferencia puede ser considerada como normal, si consideramos las edades medias de ambas poblaciones activas. La población extranjera es más joven, con una estabilidad, temporalidad y dificultades de inserción en el empleo de menores. Pero a partir 
FIGURA 6

COMPARACIÓN DE LAS TASAS DE PARO EN NACIONALES Y EXTRANJEROS EN ESPAÑA (2005-2009)

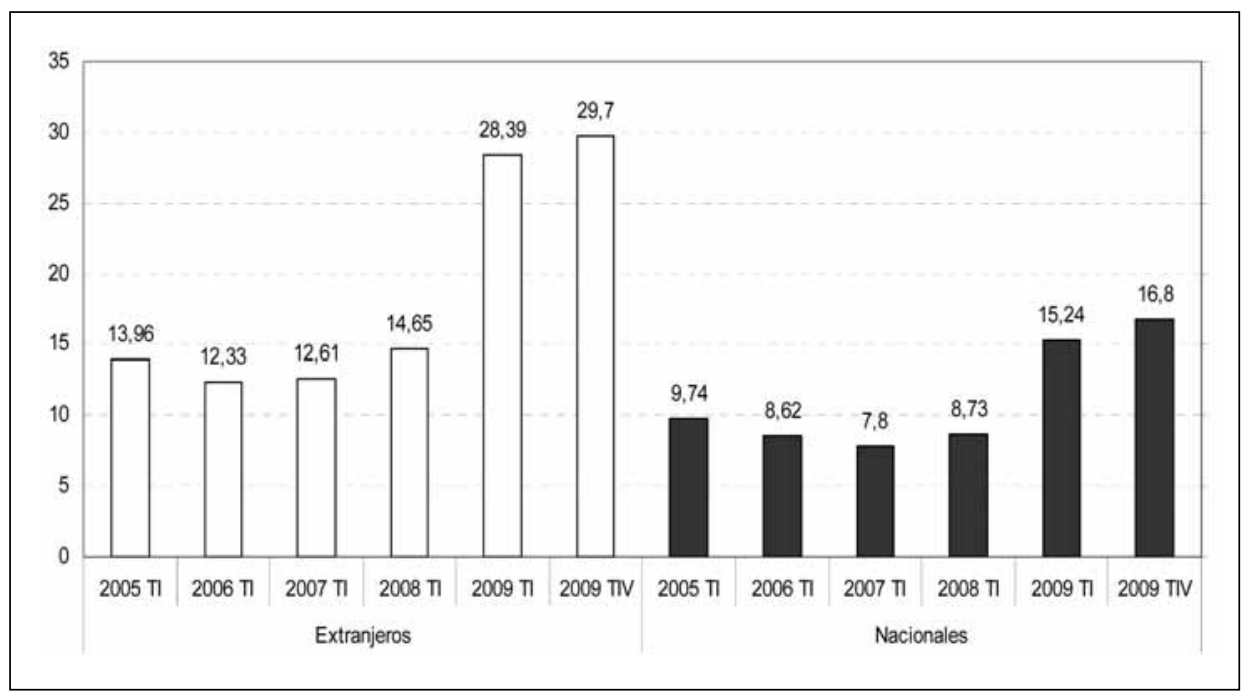

Fuente: Encuesta de Población Activa, INE www.ine.es. Elaboración propia.

del primer trimestre del año 2008 cambia la tendencia y comienza un constante distanciamiento entre las tasas de paro de ambas poblaciones. Mientras las tasas de paro de los españoles fluctúan en torno al 15\%, las de los extranjeros superan con creces el 25\%, llegando en el 2009 a casi el 30\%. (figura 7)

Otro aspecto a tener en cuenta es que el aumento de la tasa de paro en los extranjeros modifica la relación entre la tasas de paro por sexos. En el período anterior a la crisis la tasa de paro femenina fue siempre superior a la masculina. Desde el tercer trimestre del 2008 se invierte esta relación, sobrepasando la tasa de paro de los varones la correspondiente a las mujeres. Esta inversión es un fenómeno propio de la población extranjera residente en España, ya que la población autóctona no presenta variaciones, es decir, la tasa de paro femenina sigue siendo superior a la masculina. La explicación se encuentra en la repercusión directa que tiene sobre el empleo extranjero masculino la crisis de la construcción en España.

Dentro de la Unión Europea y, más específicamente, en el conjunto de los quince países que constituyen su núcleo, España es con mucho la nación más afectada por el paro derivado de la crisis económica actual. Como es un hecho 


\section{FIGURA 7}

COMPARACIÓN DE LAS TASAS DE DESEMPLEO ENTRE NACIONALES Y

EXTRANJEROS EN ESPAÑA, SEGÚN SEXO (TRIMESTRES 2005 AL 2009)

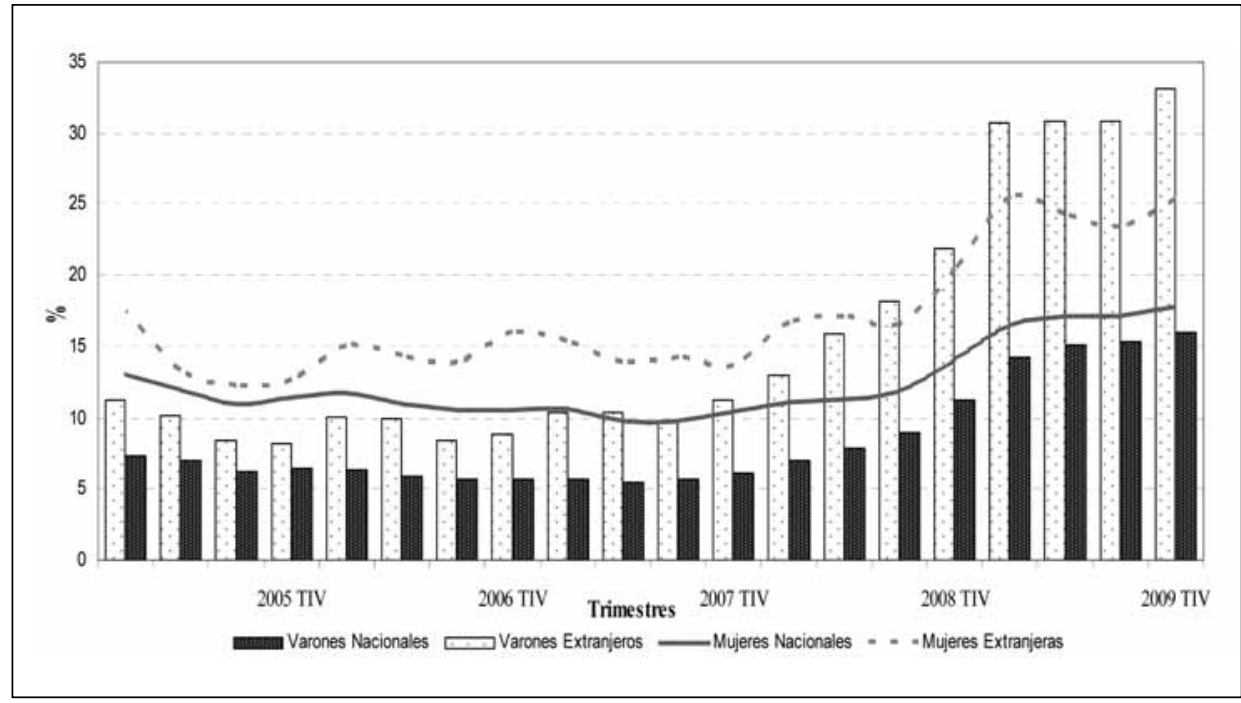

Fuente: Encuesta de Población Activa, INE www.ine.es. Elaboración propia.

que la crisis está afectando más al empleo masculino que al femenino, esto indica que el nivel medio de incorporación de la mujer al trabajo en España está por debajo de los estándares europeos. También se debe a la menor volatilidad de los trabajos desempeñados por las mujeres inmigrantes en la sociedad española. Las mujeres que trabajan en el servicio doméstico y en el cuidado de niños, mayores y enfermos se mantienen más activas que los varones inmigrantes que trabajan en la construcción, el sector agrícola, o en los servicios de menor estabilidad (restauración, turismo, etc.). Esta realidad ha tenido un resultado positivo en la fijación de los inmigrantes en España.

Pero también existe una clara diferencia entre las tasas de paro de las nacionales y de las extranjeras. En el bienio 2005 y el 2007 las tasas de paro de mujeres nacionales son entre un $4 \%$ y un $6 \%$ inferior a las de las extranjeras. Desde el comienzo de la crisis la tasa de paro de las mujeres extranjeras crece en proporciones mucho mayores que la de las mujeres nacionales llegando a ser la diferencia de hasta un $10 \%$. Dos razones, al menos, justifican esta realidad empírica: a) que la naturaleza diferencial del paro de inmigrantes y na- 
cionales se mantiene más allá de las condiciones particulares del sexo; b) que muchas extranjeras residentes en España, principalmente motivadas por el desempleo masculino, han pasado a considerarse como población dispuesta al trabajo, es decir, como población empleable, independientemente de la posterior obtención, o no, de un puesto de trabajo.

Si tenemos en cuenta que la edad media de la población activa inmigrante es menor, las tasas de paro por grupo de edad explican también su desventaja, ya que con la excepción del grupo de 16 a 19 años, las tasas de paro son inversamente proporcionales a la edad (ver figura 8).

FIGURA 8

NÚMERO DE PARADOS POR GRUPOS DE EDAD. SERIE ANUAL 2000-2009

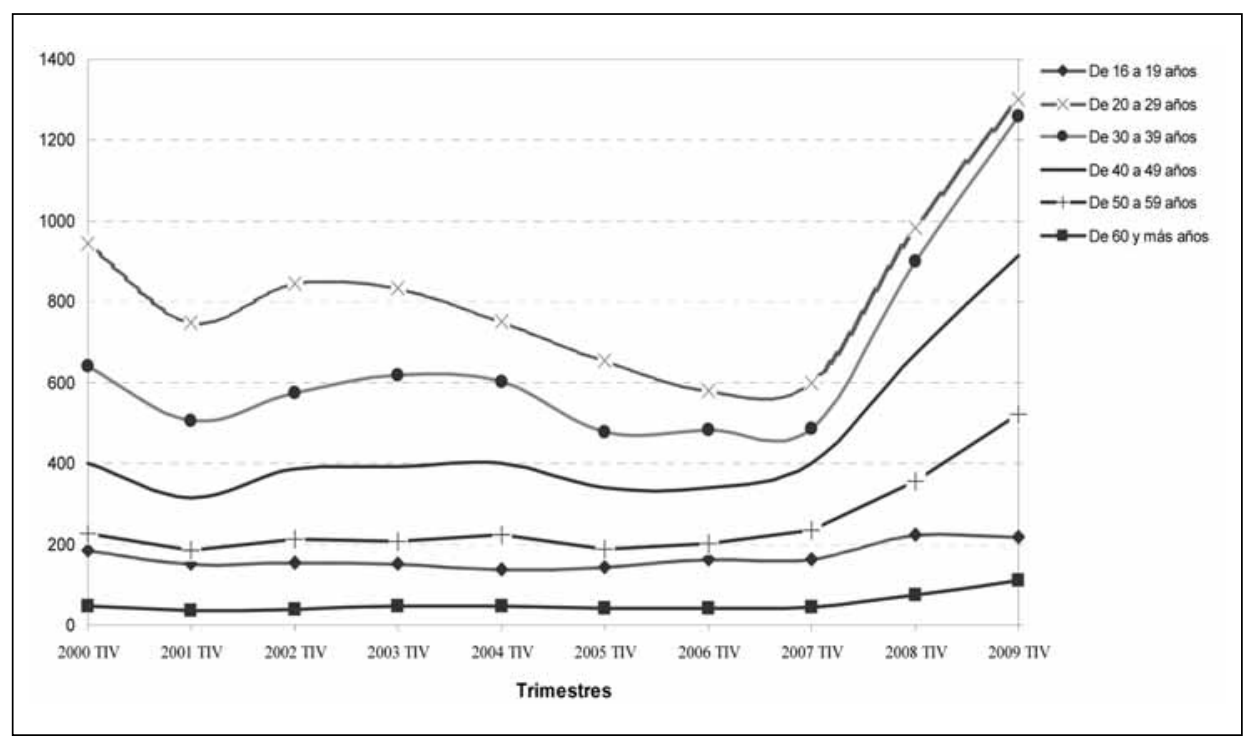

Fuente: Encuesta de Población Activa, INE www.ine.es. Elaboración propia.

También las tasas de desempleo de extranjeros varían en función de sus Comunidades Autónomas respectivas. En el período 2005-2009 (ver figura 9), la Comunidad Autónoma de Madrid es la que ha tenido una tasa de desempleo extranjero inferior, seguida de Cataluña y de la Comunidad Valenciana. Andalucía, con ligeras excepciones, es la Comunidad que presenta una tasa de paro de extranjeros más elevada. 
FIGURA 9

COMPARACIÓN DE LAS TASAS DE DESEMPLEO EN LOS EXTRANJEROS EN LAS CUATRO CCAA CON MÀS POBLACIÓN EXTRANJERA. TRIMESTRES 2005 AL 2009

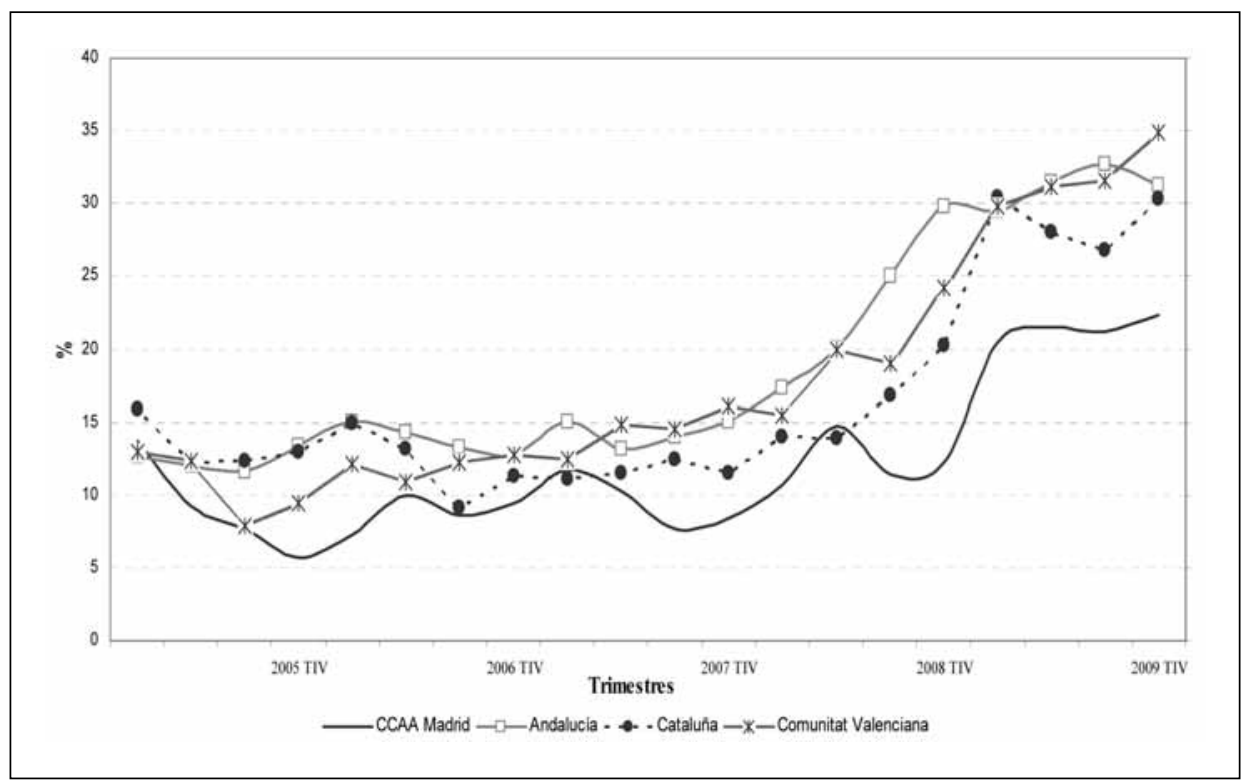

Fuente: Encuesta de Población Activa, INE www.ine.es. Elaboración propia.

Antes de iniciarse la crisis económica, la población extranjera tenía mayores posibilidades de encontrar un empleo, por su mayor flexibilidad (salarial, ocupacional, geográfica, etc.). Al mismo tiempo, la población extranjera tenía mayores probabilidades de perder el empleo. Pero, tras el inicio de la crisis económica, las diferencias en cuanto a la posibilidad de encontrar un empleo entre extranjeros y españoles casi desaparecen y, en cambio, la probabilidad de que un extranjero pierda su empleo es mucho mayor que la de un español.

En estos momentos de crisis económica, la integración de los inmigrantes representa uno de los grandes desafíos para la sociedad española, en especial porque se están incorporando ya las segundas generaciones (los hijos de quienes protagonizaron el viaje migratorio) que ya en el año 2008 representaron más del 24\% del total de los niños y niñas nacidos en España. Su plena incorporación a los procesos de movilidad, sin discriminación de ningún tipo, y su sentido de pertenencia a la sociedad de acogida, pondrán a prueba la capaci- 
dad de España para integrarles y no excluirles, descartando así el riesgo de fractura social, facilitando poner en pie un futuro de convivencia y cohesión.

Para lograrlo es necesario consolidar la prestación de los servicios básicos (salud, enseñanza, etc.), como resultado de una política fiscal adecuada que haga posible que los trabajadores extranjeros colaboren en su financiación. De la misma manera que la crisis actual influye negativamente en la creación de familias nativas, las parejas inmigrantes se ven afectadas por la incertidumbre económica, por este motivo es necesaria también una política familiar dirigida al colectivo inmigrante.

El hecho que la gran mayoría de los inmigrantes no hayan abandonado España, a pesar de la crisis y de las ayudas, tiene su respuesta en la diferencia, a pesar de todo, de la calidad de vida que España ofrece frente a las realidades sociales de los países de origen de los inmigrantes.

Con respecto a las estadísticas de paro, en la EPA del $4^{\circ}$ trimestre de 2009, se señala que, en ese trimestre, el número de hogares con todos sus miembros activos trabajando disminuye en 128.900 y se sitúa en 9.408.400. En todo el año 2009 el descenso en el número de este tipo de hogares ha sido de 690.700. Por otra parte, el número de hogares con todos sus miembros activos en paro ha aumentado en 392.800 en los últimos 12 meses, alcanzando la preocupante cifra de 1.220.000, a principios del año actual.

Según datos del Ministerio de Trabajo e Inmigración el incremento del desempleo de la población inmigrante ha sido muy acusado en el primer trimestre del 2009, pero se ha estabilizado en los siguientes. Los más optimistas piensan que nos podemos encontrar al final de ese proceso de destrucción de empleo inmigrante, desencadenado por la recesión actual.

Ciertamente, la crisis económica ha amortiguado la presión migratoria a la que se ha visto sometida España en lo que va de siglo xxi. Según fuentes del Ministerio de Trabajo e Inmigración, la población extranjera residente en España ha crecido solamente un $7 \%$ en el año 2009 , es decir, en unos 300.000 habitantes (un tercio de los cuales procedía de la Unión Europea). Esta tasa de crecimiento es la más baja en 18 años consecutivos. Sin ir más lejos, en el año 2001 por ejemplo, la tasa de crecimiento de la población residente extranjera en España fue del 23,8\%8.

\footnotetext{
${ }^{8}$ Cada vez es más frecuente utilizar la expresión transición migratoria para referirse a este cambio de intensidad en las llegadas, acompañado, probablemente, de un incremento en la capacitación profesional de los nuevos inmigrantes.
} 
Paro español y Paro europeo (2000-2009)

Como señalábamos anteriormente (figura 4) no todos los países de la UE 15 tienen, con respecto a los indicadores económicos, un comportamiento similar. Para facilitar las comparaciones se han seleccionado a los cuatro países con mayor peso demográfico y económico (Alemania, Francia, UK e Italia) y a tres países que, junto con España, forman parte de la periferia europea (Grecia, Portugal e Irlanda).

A este respecto, nos parece interesante destacar los siguientes aspectos:

- Las tasas de paro de los ocho países descienden, con alguna excepción, a lo largo del período 2001-2007, situándose en el último año en torno al $8 \%$, aunque algunos países tienen tasas claramente inferiores a este valor (Irlanda, menos de la mitad; Italia, 6\%; UK, ligeramente superior al 5\%).

- Con posterioridad a 2007, en cambio, se observan tres grupos muy distintos entre sí: En los países de mayor peso, las tasas de paro oscilan en torno al 8\% (Alemania, 7,4\%; Francia, 9,3\%; UK, 7,7\%; Italia, 8,5\%); en Grecia (10\%), Portugal (10\%) Irlanda (11,8\%) las tasas de paro crecen ostensiblemente y, finalmente, en España, la tasa de desempleo se dispara en España $(18 \%)^{9}$.

Desde un punto de vista espacial y aprovechando las herramientas de visualización que facilita la bases de datos EUROSTAT, podemos apreciar el patrón de distribución del fenómeno del desempleo en el ámbito de la Unión Europea desde el 2001 al 2009, y la excepcionalidad del caso español (ver figura 10). En fechas muy próximas a éstas, las estadísticas publicadas por el INE (ver figura 11) nos permiten obtener dos instantáneas de la importancia del desempleo en el interior del territorio español (2002 y 2009). Vemos, en el caso de España, un proceso de difusión con dos componentes fundamentales: la primera, en dirección sur-norte y la segunda, a lo largo de la cornisa mediterránea.

El INE publica para el cuarto trimestre de 2009 (EPA) los siguientes datos: Número de parados: 4.326 .500 personas (1.118.600 más que a finales de 2008); tasa de desempleo: 19\%. En el cuarto trimestre de 2009 no se registran descensos del desempleo en ninguna comunidad autónoma, observándose los mayores incrementos de paro en Andalucía (39.600 personas), Cataluña

9 Dentro de la Unión Europea sólo existe un país, Letonia, con una tasa de paro superior a la española (2009). En el momento de imprimir este artículo (abril 2010) la tasa de desempleo en España supera el 20\%. 
FIGURA 10

MAPAS DEL PARO EN EUROPA (UE-15) EN LOS AÑOS 2000 Y 20009
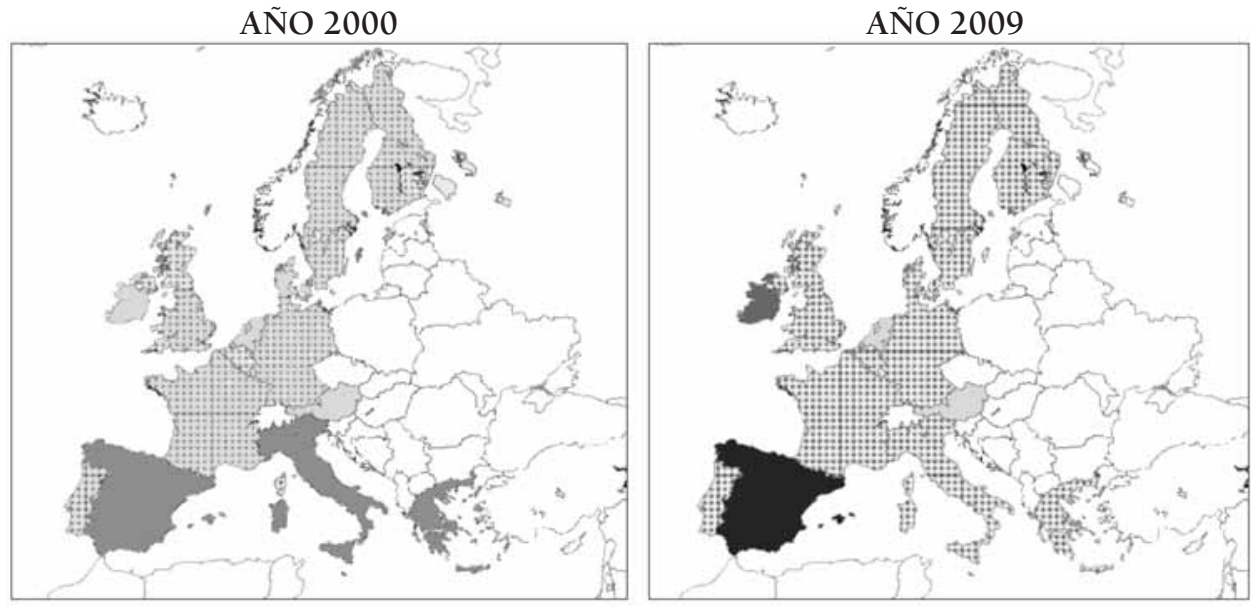

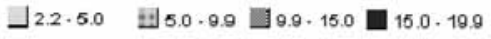

Fuente: Eurostat, http://epp.eurostat.ec.europa.eu/tgm/.

Elaboración, Eurostat (modificaciones de sombreado, son propias).

FIGURA 11

MAPAS DEL PARO EN ESPAÑA: POR CCAA. TASAS EN PORCENTAJES (2002 Y 2009)

AÑO 2002

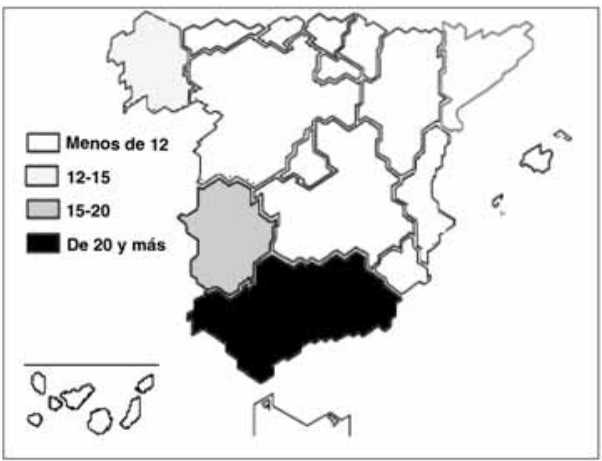

AÑO 2009

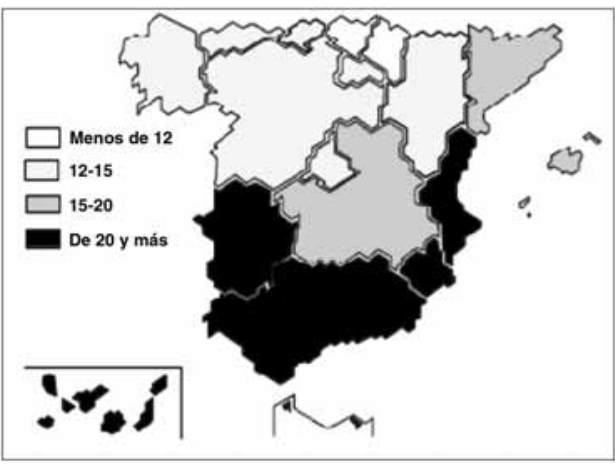

Fuente: Notas de Prensa de la Encuesta de Población Activa, INE. www.ine.es. Elaboración: INE (Cambios de color en el relleno son propios).

Estudios Geográficos, Vol. LXXI, 268, pp. 67-101, enero-junio 2010

ISSN: 0014-1496, eISSN: 1988-8546, doi: 10.3989/estgeogr.0505 
(35.900 personas) y Baleares (22.400 personas). En este marco, la tasa de actividad masculina desciende hasta el $68,14 \%$ y la tasa femenina aumenta hasta situarse en el $51,70 \%$, siguiendo la tendencia reciente que resulta de la mayor volatilidad de los trabajos desempeñados habitualmente por varones, y de la incorporación de más y más mujeres al mercado de trabajo, ahora con mayor motivo, para compensar el desempleo de algunos miembros masculinos del grupo familiar.

Según la misma fuente estadística, en el año 2009 el sector más castigado por el paro, ha sido el de la construcción, donde la ocupación baja en 378.100 personas (-17,34\%). En orden decreciente aparecen el sector industrial (361.700 personas: $-11,89 \%)$, los servicios (449.900 personas: $-3,25 \%$ :) y la agricultura (21.200 personas: $-2,64 \%)$.

El incremento del desempleo por sectores entre los inmigrantes se puede deducir por la evolución reciente de otra variable: el número de contratos a extranjeros por sector económico. En la figura 12, correspondiente a los años 2002 y 2008, se aprecia la variación interanual del porcentaje sobre los totales de los contratos extendidos a extranjeros fue del $+6 \%$ en los servicios, $-1 \%$ en la construcción, - $2 \%$ en la agricultura y -3\% en la industria. Estos datos reflejan que también entre los inmigrantes, se ha producido un cierto trasvase hacia el sector servicios en el marco de la crisis económica actual.

Por otra parte, merece la pena mencionar los cambios producidos, en los últimos años, en la distribución de los trabajadores extranjeros por cuenta ajena y por cuenta propia. En la figura 13, además de la aplastante mayoría que suponen los trabajadores extranjeros por cuenta ajena, se aprecia un ligero incremento de los trabajadores por cuenta propia $(+1 \%)$ en dos años, entre el 1 de enero de 2007 y el 31 de diciembre de 2008. Realmente no pensamos que se trate de una incursión de los inmigrantes en el dominio del autoempleo sostenible sino de inmigrantes en paro, que deciden intentar otras formas de ganarse la vida, como autónomos, a la espera de una coyuntura económica más favorable.

De acuerdo con los analistas europeos, la crisis del desempleo español tiene dos factores claros y fundamentales:

- Por un lado, la importancia del sector inmobiliario en la economía española (ver figura 14) y el importante desfase entre los ritmos de construcción y de ocupación de viviendas (burbuja inmobiliaria).

- Por otro, la segmentación del mercado laboral en dos estratos claramente diferenciados: el de los contratos permanentes, defendidos por los sindicatos mayoritarios y el de los contratos temporales, que se realizan nor- 
FIGURA 12

\section{CONTRATOS REGISTRADOS A TRABAJADORES EXTRANJEROS POR SECTOR DE ACTIVIDAD}

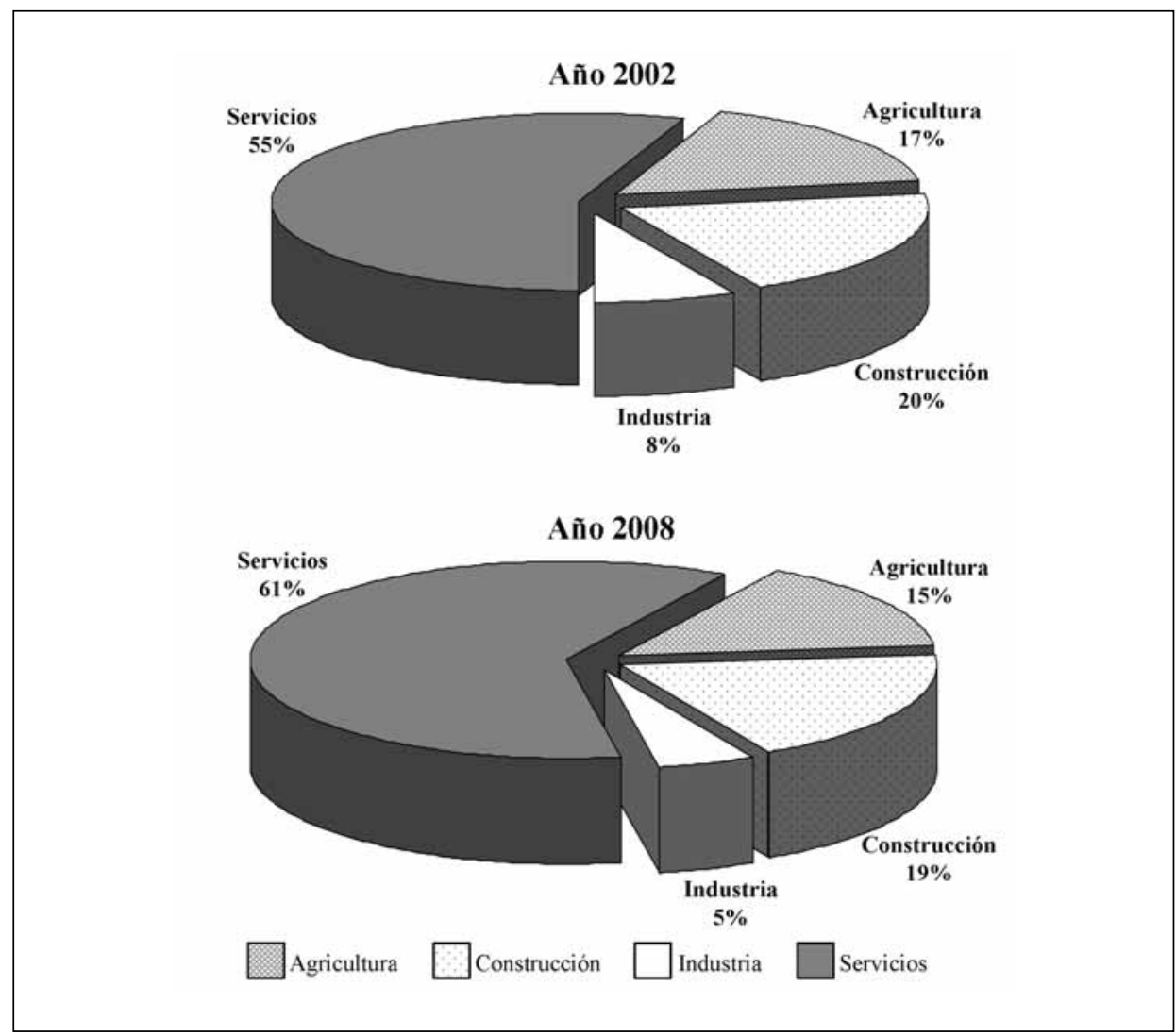

Fuente: Anuarios estadísticos de la Secretaria de Estado de Inmigración y Emigración, http://extranjeros.mtin.es/es/InformacionEstadistica/Anuarios/Anuario2008.html,. Elaboración propia.

malmente, a jóvenes o inmigrantes. La segmentación del mercado laboral, en opinión de los expertos, justificaría por si sola la crisis de desempleo española, por tratarse de una perturbación mayor del principio de libre competencia que se requiere en todos los mercados de una economía no intervenida. Las PYMES son casi siempre las más afectadas, atrapadas entre los altos salarios de sus empleados y las crecientes dificultades para conseguir créditos razonables. 


\section{FIGURA 13}

\section{ALTAS EN LA SEGURIDAD SOCIAL DE TRABAJADORES EXTRANJEROS POR TIPO DE DEPENDENCIA LABORAL}

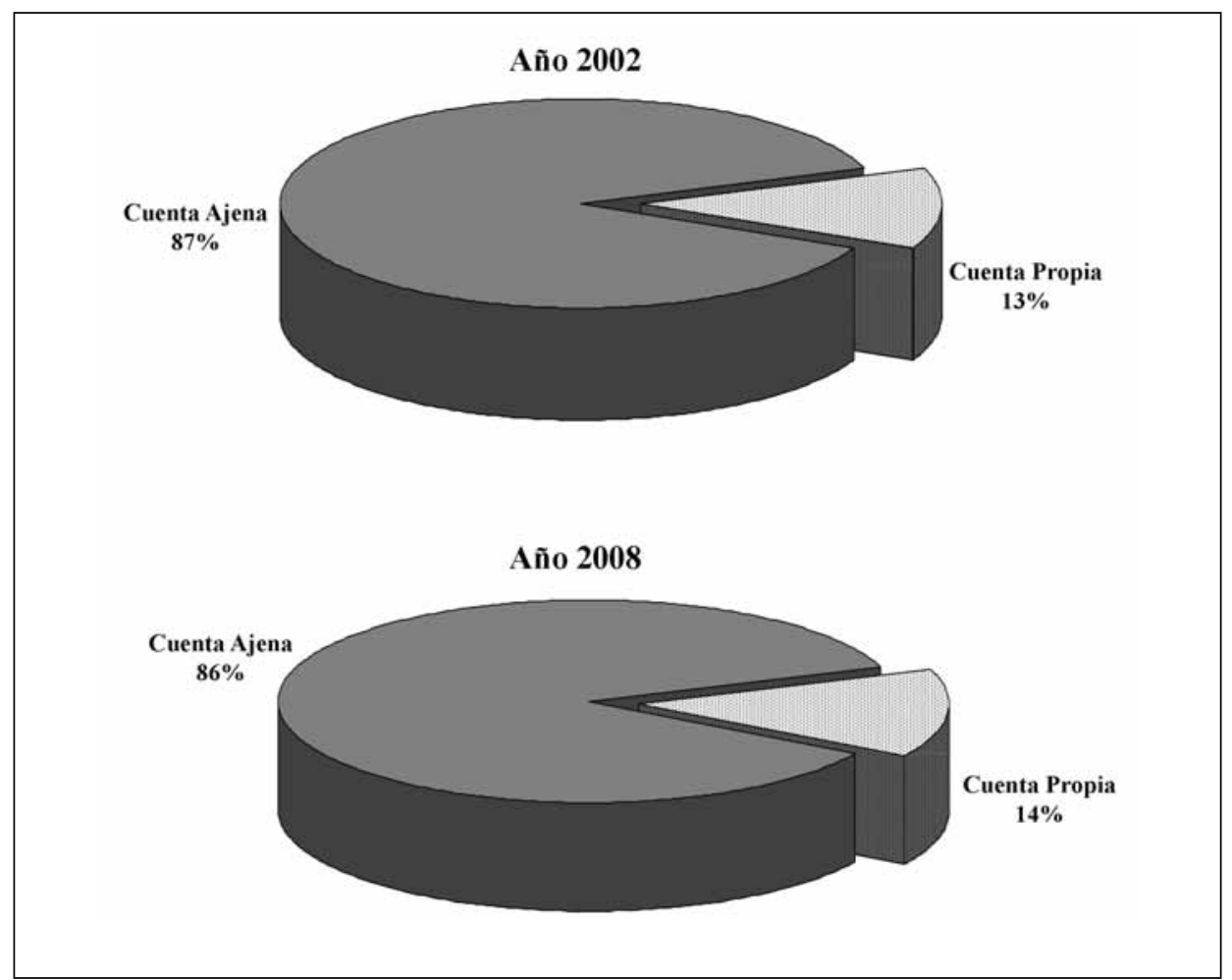

Fuente: Anuarios estadísticos de la Secretaria de Estado de Inmigración y Emigración, http://extranjeros.mtin.es/es/InformacionEstadistica/Anuarios/Anuario2008.html,. Elaboración propia.

En su informe de 2008 el Banco de España analiza en profundidad el impacto de la crisis financiera en la economía española. Sus conclusiones principales coinciden con las de los analistas europeos, pero existen diferencias de matiz, que merece la pena registrar en este artículo.

Durante los años 1999-2006 se produjo es España un fuerte impulso de la demanda de bienes de consumo, que fue satisfecha por un aumento importante de la oferta, generando tantos puestos de trabajo que fue necesario contar con la incorporación de muchas mujeres al mercado laboral y con la entrada de trabajadores extranjeros en proporciones excepcionales. Pero el au- 
FIGURA 14

PARTICIPACIÓN DE LA CONSTRUCCIÓN EN LA GENERACIÓN DE VALOR (\% PIB). SERIE 2000-2009. EU-15 Y SELECCIÓN DE PAÍSES

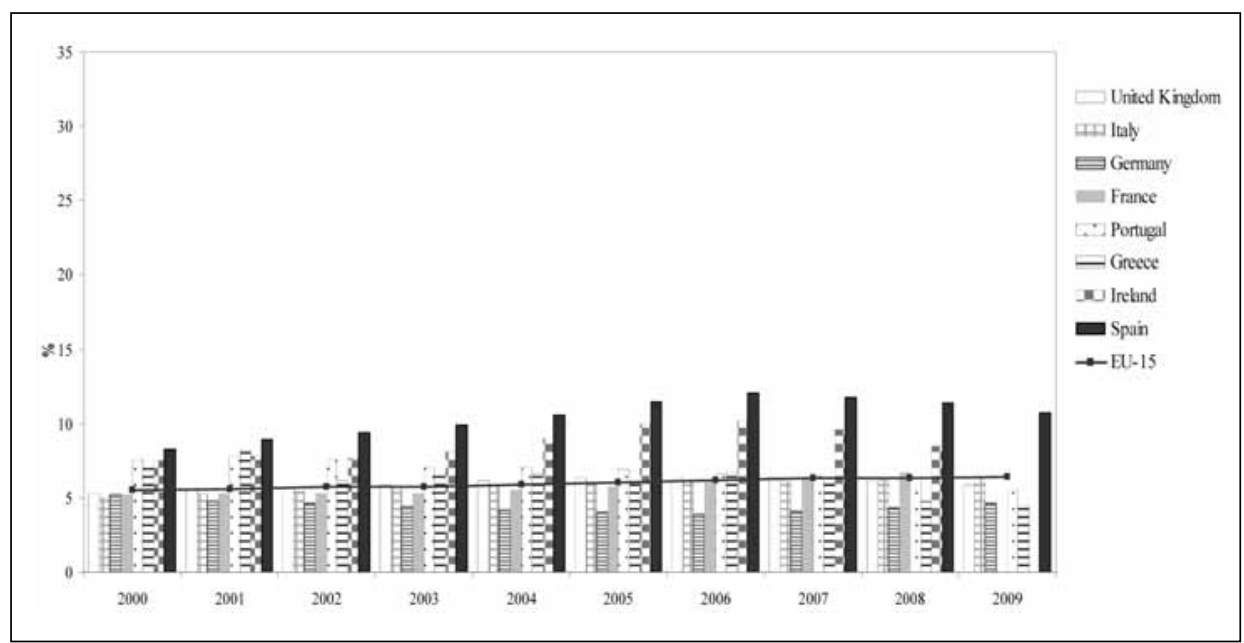

Fuente: Eurostat, http://epp.eurostat.ec.europa.eu. Elaboración propia.

mento de la capacidad productora de España en esos años fue debido a la concentración de mano de obra en sectores que requieren gran intensidad laboral. La productividad de la economía española, en cambio, no experimentó excesivos avances, siendo este hecho una de las causas del elevado paro actual. Al final, el aumento de la demanda era tal que empezó a generar un progresivo endeudamiento con el exterior: mientras que en 1996 la economía española no precisaba de endeudamiento exterior, en 2008, la necesidad de recursos exteriores se situó en el 9,1 del PIB.

Así la crisis económica sólo ha acelerado un proceso cuya gestación se venía observando durante un período de crecimiento prolongado: a) la concentración de recursos financieros en el sector inmobiliario ${ }^{10}$ (como reflejan la

${ }^{10}$ Es importante explicar el crecimiento explosivo del sector de la construcción en España, pues se trata de un fenómeno excepcional. El Banco de España señala tres causas fundamentales:

- El crecimiento exagerado de la población española debido a una inmigración masiva que ha tenido lugar en la primera década del siglo XXI.

- Las promociones de viviendas turísticas.

- La necesaria construcción de infraestructuras, propia de un período de convergencia con el resto de la UE. 
evolución del empleo en el sector desde 1999 con un 9,5\% del empleo total, hasta 2007 con un 13,2\% del empleo total; y el crecimiento ininterrumpido de los precios de la vivienda, cuya tasa de crecimiento en el período 1995-97 fue del 1\%, y del 10\% en el período 1997-2007) y b) el fuerte endeudamiento. La aceleración ha sido tan intensa que ha desbordado todas las previsiones. La crisis internacional está reduciendo el déficit exterior y el peso de la construcción, es cierto, pero con un coste social difícil de soportar, porque el descenso general de la actividad productiva está destruyendo la extraordinaria capacidad de creación de empleo que tenía la economía española.

En España, como en el resto de los países de la zona Euro, son necesarios ajustes complementarios, para recuperar su posición económica competitiva: a) Crecimiento de la productividad, b) Moderación de los márgenes empresariales, c) Moderación de los costos laborales, y d) Flexibilización del mercado laboral, para que se puedan llevar a cabo más fácilmente los cambios de puesto de trabajo. La crisis internacional ha supuesto una crisis de confianza importante, que se refleja en el endurecimiento de las condiciones crediticias, el aumento de los costes de intermediación financiera y, por ello, en el descenso de la actividad y productividad económica.

La crisis podría haber tenido en España alguna consecuencia positiva, como, por ejemplo, la movilización de trabajadores de los sectores menos productivos a los más eficientes, pero esto se ha visto impedido por la rigidez del mercado laboral. Por otra parte, la crisis ha repercutido negativamente en el recorte de las inversiones públicas y privadas en I+D. Además se han desvalorizado los activos inmobiliarios, lo que significa una bajada en la riqueza de las familias y una desaceleración del consumo.

La salida de la crisis requiere una regulación laboral más favorable a las nuevas contrataciones y a la recuperación de la productividad a medio y largo plazo. En particular, se requiere una nueva legislación sobre contratos de trabajo y sobre su negociación — colectiva o no-. Como esta legislación no se puede improvisar, mientras se avanza en esta reforma laboral, es necesario encontrar medidas transitorias que puedan frenar la destrucción del empleo que se está produciendo. Hasta ahora, el gobierno se ha centrado en los incentivos a la contratación y en la protección del desempleo, pero a la vista está que no son suficientes. Hay que explorar también la introducción de nuevas formas de contratación y la prevalencia de los acuerdos en las empresas sobre los convenios de ámbito superior.

Ahora bien, si la Unión Europea es ya un área de libre circulación de bienes, personas y capitales, y si, dentro de ella, la zona Euro sólo admite una política monetaria común, deberemos aproximarnos a los diferentes estados 
miembros como si fueran — desde el punto de vista económico, realmente lo son- regiones dentro de un estado plurinacional. Quiere esto decir que las características negativas, y las positivas también, de la economía de un determinado país miembro no es simplemente un vicio o una virtud de ese país aisladamente considerado, sino de todo el conjunto.

En el caso que estamos examinando: el del escandaloso paro existente en España, tan correlacionado con la quiebra del sector de la construcción, tiene también una lectura a escala europea. La construcción se ha desarrollado intensamente en los últimos años en España por varios motivos: especulativos; demográficos (la necesidad de albergar a una población en rápido aumento por inmigración extraeuropea: un fenómeno que todos los analistas consideran necesario para la viabilidad socioeconómica de Europa); turísticos (para mejorar y ampliar el parque turístico que consumen, en un alto porcentaje, los nacionales comunitarios) y por la mejora de las infraestructuras (tarea imprescindible para todo estado que se incorpora a una organización enriquecida y altamente estandarizada). Está llegando el momento en el que el llamado análisis regional no se refiera ya a espacios infranacionales sino más bien a conjuntos supranacionales. En la crisis actual, si cada país europeo sólo pretendiera mejorar sus parámetros macroeconómicos, con independencia de los demás, estaríamos asistiendo a una pérdida preocupante de visión política en los miembros de la UE.

\section{NUEVAS POLÍTICAS DE CONTENCIÓN Y RETORNO DE INMIGRANTES EN ESPAÑA}

A raíz de la fuerte contracción del mercado laboral español se han formulado políticas explícitas (y también implícitas) para, por lo menos, contener la llegada de nuevos trabajadores extranjeros que no encontrarían empleo adecuado en España. Además, se han articulado procedimientos públicos, o promovidos por el tercer sector, de retorno voluntario.

En un período de recesión económica resulta más que razonable el intento de contrarrestar la inercia de los flujos migratorios, establecidos en una coyuntura totalmente distinta. En cambio, la expulsión, o retorno obligatorio, de los inmigrantes instalados ya en España constituiría una medida desproporcionada, arbitraria y, a la postre, empobrecedora. España necesita una gran mayoría de las personas que se han instalado en su territorio en los últimos veinticinco años, colaborando a su crecimiento demográfico, económico y sociocultural, convirtiendo a España en un país totalmente distinto, con una proyección internacional indiscutible. 
En este apartado resumimos el contenido de los dos planes de retorno asistido que se han ofrecido en España a los inmigrantes, y cuál ha sido la respuesta obtenida. También se repasan las principales características de la nueva Ley de Extranjería 2/2009, en lo referente a las políticas migratorias que inciden en la situación actual de recesión económica generalizada.

El programa de retorno voluntario de trabajadores extranjeros no comunitarios se ofrece a todos aquellos inmigrantes en situación de desempleo y que procedan de países extracomunitarios con los cuales España haya firmado convenios bilaterales en materia de Seguridad Social. Las personas que se acojan podrán cobrar por anticipado todas sus prestaciones por desempleo y computar todas las cotizaciones realizadas en España y en origen a efectos de una futura pensión.

Este sistema de abono de las prestaciones por desempleo se hace en dos plazos: el 40\% en España una vez reconocido el derecho y, el 60\% restante, en el país de origen, entre treinta y noventa días naturales desde la fecha del primer pago de la prestación. Los perceptores de la ayuda se comprometen a retornar a su país de origen en un plazo máximo de treinta días naturales a partir de la fecha del primer pago de la prestación, en compañía de los familiares reagrupados sin autorización de residencia independiente. Además, los retornados no podrán volver a España en un plazo de tres años, para residir o realizar actividad lucrativa.

El Ministerio de Trabajo e Inmigración ha publicado que la respuesta al programa ha sido muy limitada: sólo unos cinco mil solicitantes. Cuando se conoce que, al menos, un millón de inmigrantes se encuentran desempleados, este resultado pone de manifiesto que la inmensa mayoría de los inmigrantes no van a retornar a sus países fácilmente. Muy probablemente no volverán apresuradamente o, simplemente, no volverán. Existen muchas razones que lo justifican: la más importante de ellas (que las resume aceptablemente) es que se consideran parte del sistema socioeconómico español, por ello deben compartir momentos de expansión y, también, de recesión.

Paralelamente, se ha diseñado el programa PREVIE, por iniciativa de la Organización Internacional para las Migraciones (OIM), financiado por el IMSERSO y desarrollado en colaboración con el Ministerio del Interior. Este programa está dirigido también a inmigrantes que desean voluntariamente volver a su país de origen, pero, en este caso, que se encuentren en estado de seria vulnerabilidad social. El programa no restringe su actuación a los casos de inmigrantes de países con los que España tiene suscritos acuerdos bilaterales en materia de Seguridad Social. Este programa ofrece la siguiente asistencia gratuita: información y orientación sobre el retorno; ayuda en la tramitación de la 
documentación necesaria para el retorno; billetes para el retorno; pequeña cantidad de bolsillo para el viaje; posibilidad de ayuda económica para la reintegración en el país de origen y seguimiento de los retornados.

Para acogerse al programa es requisito imprescindible presentar un informe de los servicios sociales del ayuntamiento en el que reside (que certifique la situación de seria vulnerabilidad social) y firmar un impreso de voluntariedad de retorno.

La nueva Ley de Extranjería 2/2009 está justificada por tres motivos: a) el carácter desfasado de la ley vigente; b) la necesidad de incorporar las últimas directivas inmigratorias de la UE; y c) el cambio sustancial que se ha producido en la sociedad española desde la publicación de la última ley orgánica de extranjería.

La nueva ley tiene dos ejes de actuación fundamentales. El primero consiste en la estructuración de las competencias en materia inmigratoria de los distintos escalones de la administración: nacional, autonómico y municipal. En esta línea, la ley establece, por primera vez en la historia reciente, que las distintas Comunidades Autónomas pueden desarrollar políticas migratorias independientes, es decir, pueden conceder permisos de estancia por trabajo, reagrupación familiar, etc. Hasta ahora, la concesión de permisos de residencia estaba reservada al gobierno central, así como la vigilancia de las zonas fronterizas, por motivos de seguridad nacional. No obstante quedar reflejado en la ley, no existe consenso parlamentario sobre esta atomización de la política migratoria española.

El otro eje de actuación consiste en facilitar al máximo el diálogo entre la administración del estado, los sindicatos, las confederaciones empresariales y los inmigrantes organizados asociativamente.

Reforzando estos dos ejes de actuación, la ley define cuatro objetivos fundamentales:

- La lucha contra la inmigración irregular y la trata de personas.

- La ordenación de los flujos de inmigrantes laborales, recurriendo a procedimientos como el de la contratación en origen, que ha dado resultados muy positivos en el período inmediatamente anterior a la crisis. También se propone una regulación más detallada de la situación nacional de empleo en el catálogo de ocupaciones de difícil cobertura. Considera infracciones graves o muy graves trabajar sin permiso o no dar de alta al trabajador en la Seguridad Social.

- Garantizar a los extranjeros el ejercicio pleno de los derechos fundamentales, entre ellos, los de educación (antes de los 18 años), reunión, manifestación, asociación, sindicación y huelga. 
- Facilitar, por todos los medios, la integración de los inmigrantes en la sociedad española, en la línea de las directivas de la Unión Europea, que apuestan por la convivencia de identidades y culturas. En esta línea se articulan nuevas fórmulas de reagrupación familiar y se propone reforzar los mecanismos de integración en momentos conflictivos, como el actual.

\section{PolíticAS DE CONTENCIÓN Y RETORNO EN EUROPA}

España no es un caso aparte en el conjunto de los países europeos, en los que la recesión económica está afectando más a los inmigrantes que a los nativos. Por ello, también en Europa se están produciendo tensiones sociales, que deben ser corregidas por políticas de integración y de mercado. En España, la crisis ha perjudicado más intensamente a los trabajadores inmigrantes porque, independientemente de su nivel de formación, ocupan puestos de trabajo poco cualificados (ver figura 15) y además trabajan en los sectores más dañados por la recesión, como la construcción.

En Europa, también, muchos inmigrantes no quieren volver a sus países de origen, ya que las posibilidades de prosperar, de encontrar posibles nuevos empleos, y las condiciones de calidad de vida, incluyendo Servicios Públicos y Sociales como la Educación y la Sanidad, son más elevadas en los países de acogida que en los de origen (tanto si son de fuera de la UE, como si son originarios de los países menos prósperos de la UE: países del Este).

Muchos inmigrantes no pueden volver a sus países de origen, ya que no cuentan con los medios económicos para afrontar el regreso. Este no es el caso de los inmigrantes de países del Este, que forman parte de la UE, que pueden volver a sus respectivos países, sabiendo que pueden regresar a los de acogida sin problemas, cuando la situación económica sea más próspera. También hay que tener en cuenta otras motivaciones que originaron la emigración: las relaciones sociales o familiares ya establecidas en el país de acogida, las inversiones realizadas, etc. Además, en el caso de los irregulares, temen que luego no puedan volver a entrar de nuevo. No obstante lo cual, es previsible que la reducción de oportunidades en los países receptores sí tenga efectos, a corto plazo al menos, en la contracción de las migraciones hacia y dentro de países de la UE.

En términos generales, los países europeos han llevado a cabo una serie de actuaciones políticas para controlar las migraciones, por ejemplo, requerir temporalmente la condición de tener una oferta de trabajo para aquellos puestos que actualmente no la requieran. Esto facilitará el acceso a estos puestos de trabajo a personas cualificadas para los mismos y con elevadas posibilida- 
FIGURA 15

CONTRATOS REGISTRADOS A TRABAJADORES EXTRANJEROS EN ESPAÑA, POR GRUPO DE OCUPACIÓN (2003-2008)

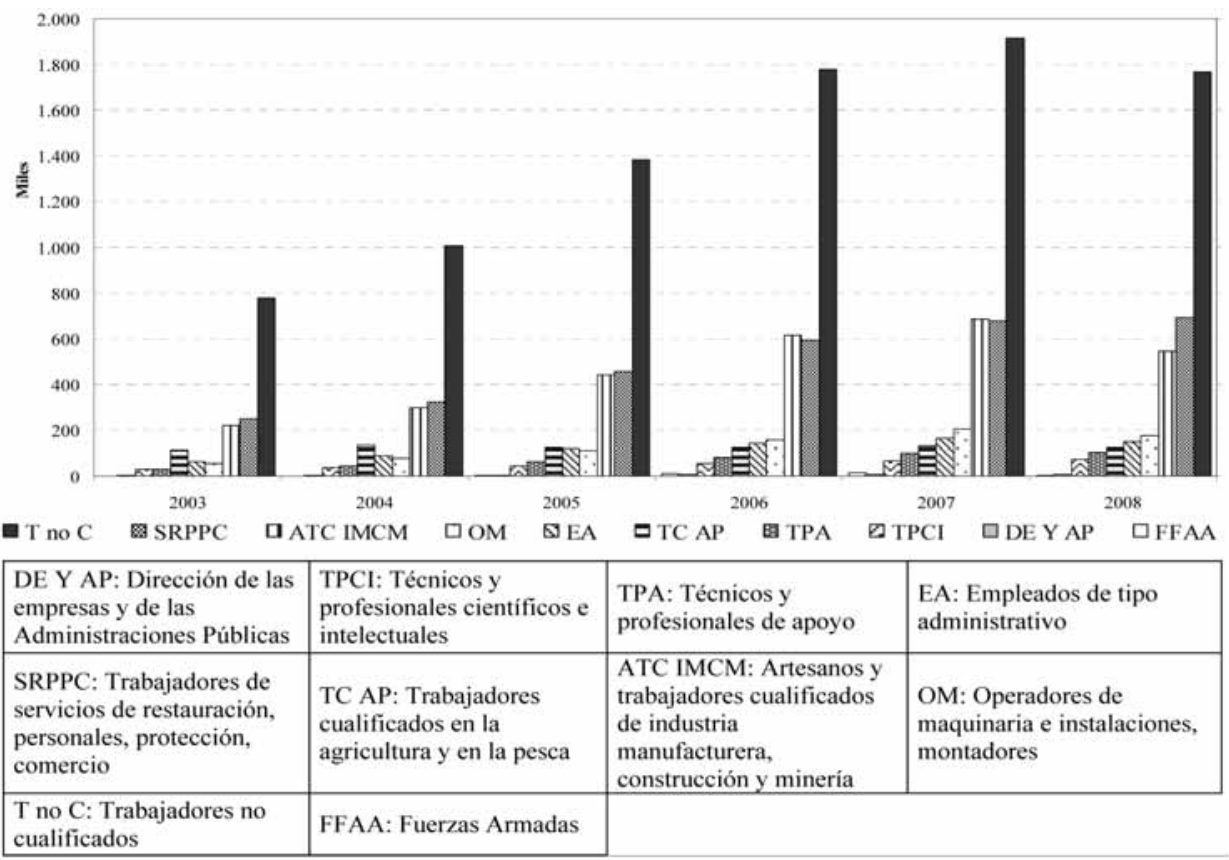

Fuente: Anuarios estadísticos de la Secretaria de Estado de Inmigración y Emigración,

http://extranjeros.mtin.es/es/InformacionEstadistica/Anuarios/Anuario2008.html,. Elaboración propia.

des de integrarse en la sociedad. También se trata de evitar el conocido Turismo de Prestaciones Sociales.

En otros casos, los gobiernos han tomado medidas para que las migraciones cíclicas sean más atractivas a los inmigrantes: así se permitiría a los trabajadores volver a sus países de origen en tiempos de desaceleración económica, al tiempo que se les facilitaría el retorno a los países de acogida en tiempos de prosperidad económica.

Igualmente, se han establecido controles en el mercado laboral para ayudar tanto a los trabajadores nativos poco cualificados, como a los inmigrantes que ya están asentados en el país de acogida.

Por ejemplo, el Reino Unido, para reducir o frenar el acceso a sus mercados laborales a través de la UK Home Office, ha endurecido las condiciones para 
lograr empleos de puestos de trabajo que requieren profesionales altamente cualificados (enfermeras, ingenieros), obligando a las empresas que los contratan a ofertar esos puestos a los trabajadores residentes (a través del Servicio Nacional de Empleo, Job Centre Plus), antes de traer trabajadores de fuera. Del mismo modo, para dificultar o, en su caso, endurecer los requisitos de admisión, se ha revisado el sistema de puntos, para que sea más complicado obtenerla, especialmente en el caso de trabajadores poco cualificados, restringiéndose así la entrada de este tipo de personas. En el caso de trabajadores muy cualificados, se obliga a estar en posesión de un Master para percibir un salario de $£ 20.000$.

Otros países europeos han tomado medidas más radicales. En Italia se ha aprobado una legislación que criminaliza la inmigración irregular y deniega el acceso a Servicios Públicos a los trabajadores irregulares. Además, se han autorizado patrullas civiles que colaboran con la Policía en cuanto a inmigración ilegal. Francia, por su parte, ha llevado a cabo una serie de redadas contra el empleo de ilegales, con el fin de trasladar esos trabajos que realizaban los irregulares a trabajadores legales desempleados.

Como España, la República Checa, basándose en un programa que realizó Francia en 1977, para repatriar trabajadores inmigrantes, está ofreciendo una serie de beneficios económicos a algunos, a cambio de su promesa de que no regresarán en un período de tiempo. Todos estos programas han tenido muy poco éxito, ya que como anteriormente se apuntó, los beneficios y ventajas que obtienen quedándose, aún estando desempleados, son muy superiores a los que encuentran en sus países de origen. Por su parte, el Reino Unido y Francia están experimentando con una variante de este concepto: ofrecer ayuda a los inmigrantes antes incluso de que lleguen. Así, ambos gobiernos anunciaron en julio de 2009 que ofrecerían un billete de avión de regreso a casa, 2.000 euros en metálico, y ayudas y asesoramiento para el realojo, para aquellos inmigrantes que, estando en Calais esperando para entrar ilegalmente en Reino Unido, así lo deseasen.

\section{A MODO DE CONCLUSIÓN}

Con el advenimiento de la crisis económica internacional, en España se deja atrás un período de cerca de 15 años de crecimiento económico sostenido. Este ciclo expansivo tuvo sus principales motores en la construcción de viviendas y nuevas infraestructuras y en el aumento demográfico por inmigración. Hoy la crisis socava lo logrado con cambios importantes en el mercado 
laboral, con alzas en la tasa de desempleo general y transformaciones estructurales en el comportamiento de la población activa.

En este escenario, el principal colectivo que se ha visto afectado es la población extranjera residente en España. Participantes de la estructura más precaria y temporal del mercado del trabajo, esta población acusa tasas de desempleo que doblan las de los nacionales españoles. Como consecuencia, se observa en este colectivo una reestructuración en las economías familiares mucho más profunda que en el resto de la sociedad, junto con una contención en el número de nuevos inmigrantes.

Ante estos acontecimientos, el Estado español se ha visto en la necesidad de reorientar su política migratoria. Por una parte, se advierte la necesidad de consolidar los procesos de integración de la población extranjera residente, asegurando su acceso a las prestaciones sociales (salud, educación, asistencia de desempleo, etc.) y, descentralizando la gestión de la migración, acercar las funciones del estado de bienestar a las familias y las personas.

Por otra parte, se ha visto en la necesidad de diseñar mecanismos de contención de los flujos migratorios, respetando la normativa internacional y el estado de derecho, para el retorno voluntario de la población inmigrante. Si bien, el éxito de estas iniciativas de contención es más bien parcial, puestas en el contexto europeo, responden al canon de las medidas que el resto de los países - en situaciones similares - de la UE han tomado, pero con un énfasis en garantizar los derechos de estos nuevos ciudadanos.

El Estado español no puede desconocer su responsabilidad hacia la población inmigrante y busca consolidar modelos de gestión de su inmigración, sujetos a los derechos de libre circulación y de ciudadanía internacional. Estas poblaciones que fueron el reflejo de la bonanza económica española, hoy son la imagen de una sociedad en crisis. Es posible que estas personas que hoy deciden permanecer en España sean fuente o eslabón clave de la futura recuperación económica.

Finalmente, las repercusiones de la crisis en España y su población inmigrante deben ser leídas en clave europea. En ese sentido, en la actual Europa, el análisis regional no se refiere ya a espacios infranacionales sino más bien a conjuntos supranacionales. En la crisis actual, si cada país europeo sólo pretendiera mejorar sus parámetros macroeconómicos, con independencia de los demás, estaríamos asistiendo a una pérdida preocupante de visión política en los miembros de la UE. El devenir de la crisis griega es hoy el mejor ejemplo.

Recibido: $12 / 04 / 2010$

Aceptado: 10/05/2010

Estudios Geográficos, Vol. LXXI, 268, pp. 67-101, enero-junio 2010

ISSN: 0014-1496, eISSN: 1988-8546, doi: 10.3989/estgeogr.0505 


\section{BIBLIOGRAFÍA}

Aja, E., Arango, J. y Oliver, J. (Dir.), (2007): “Anuario de la inmigración en España 2006". CIDOB, Barcelona.

Aja, E., Arango, J. y Oliver, J. (Dir.), (2009): "La inmigración en la encrucijada. Anuario de la inmigración en España 2008”. CIDOB, Barcelona.

Aja, E., Arango, J. y Oliver, J. (Dir.), (2010): "La inmigración en tiempos de crisis. Anuario de la inmigración en España 2009”. CIDOB, Barcelona.

Arango, J., (2005): "Dificultades y dilemas de la política de inmigración". Arbor: Ciencia, pensamiento y cultura, $\mathrm{n}^{\circ}$ 713, 2005, pp. 17-25, CSIC, Madrid.

Arango, J., (2006): "Europa y la inmigración: una relación difícil". Migraciones: nuevas movilidades en un mundo en movimiento, coord. Por María Cristina Blanco Fernández de Valderrama, p. 91-114, Anthropos, Barcelona.

Banco de España, (2008): INFORME ANUAL 2008, Capítulo 2. El impacto de la crisis financiera sobre la economía española, pp. 47-70.

Barrett, A., McGuinness, S. and O’Brien. M., (2008): "The Immigrant Earnings Disadvantage across the Earnings and Skills Distributions: The Case of Immigrants from the EU's New Member States in Ireland". Institute for the Study of Labor, Bonn.

Camarota, S.A., (2003): "Immigration in a Time of Recession: An Examination of Trends Since 2000". Backgrounder, Center for Immigration Studies, 10 p.

Castles, S., (2009): "Migration and the Global Financial Crisis: A Virtual Symposium. Update 1.A: An Overview", http://www.age-of-migration.com/uk/financialcrisis/updates/la.pdf

Cebrián, J. A., Bodega, M. I. y Martín Lou, M. A., (2008): "Back to Europe: Geografía de una inmigración sin precedentes". Revista Geográfica, Instituto Panamericano de Geografía e Historia, no 144, pp. 25-55.

Dobson, J., Latham, A. and Salt, J., (2009): "On the Move? Labour Migration in Times of Recession". Policy Network Papers, London.

Favell, A., (2008): "The new face of East-West migration in Europe". Journal of Ethnic and Migration Studies, 34 (5): 701-716.

Fix, M., Papademetriou, D. G., Batalova, J., Terrazas, A., Yi-Ying Liu, S. and Mittlestadt, M., (2009): "Migration and the Global Recession". Migration Policy Institute, $131 \mathrm{p}$.

INE., (2009.): Encuesta de la Población Activa (EPA), $4^{\circ}$ trimestre.

Izquierdo, A y León, S., (2008): "La inmigración hacia dentro: argumentos sobre la necesidad de coordinación de las políticas de inmigración en un Estado multinivel". Política y sociedad, vol. 45, número 1, Universidad Complutense, Madrid.

Krings, T., Bobek, A., Moriarty, E., Salamońska, J. and Wickham, J., (2009): "New Times? Economic Crisis, geo-political transformation and the emergent migration order. Defying the recession? Polish migrants in Post-Celtic Tiger Ireland". Centre on Migration, Policy and Society, University of Oxford, 15 p. 
Martin, P., Abella, M. and Kuptsch, C., (2006): Managing Labour Migration in the Twenty-First Century. New Haven/London, Yale University Press.

Martin, P., (2009): "The Recession and Migration: Alternative Scenarios". International Migration Institute Working Papers, Oxford.

OECD, (2009): International Migration Outlook 2009. Organisation for Economic CoOperation and Development, Paris.

Oliver Alonso, J., (2006): "Inmigración y mercado del trabajo en 2006: Razones de la acentuación del choque inmigratorio". Anuario la inmigración en España 2006. CIDOB, Barcelona.

Papademetriou, D. G., Sumption, M. and Somerville, W., (2009): "Migration and the Economic Downturn: What to expect in the European Union. Migration Policy Institute, $19 \mathrm{p}$.

Recchi, E. (2008): "Cross-state mobility in the EU: trends, puzzles and consequences". European Societies, 10, (2): 197-224.

Rogers, A, Anderson, B. and Clarke, N., (2009): "Recession, Vulnerable Workers and Immigration: Background Report". Centre on Migration, Policy and Society, Oxford.

\section{RESUMEN}

Repercusiones de la crisis económica internacional en la política inmigratoria española. Precedido por un flujo notable de inmigrantes en la últimas dos décadas del siglo xx, el incremento de la población extranjera residente en España a partir del año 2000 ha sido realmente extraordinario. En 1999 la cifra de residentes extranjeros en España era de 750.000 personas (el 1,86\% del total de la población). Diez años más tarde los extranjeros residentes en España son más de 5,5 millones (el 12\% de la población total). Pero a partir del año 2007se han modificado los flujos de inmigrantes laborales, como consecuencia de la recesión económica mundial. Naturalmente, las llegadas de inmigrantes laborales a España se han reducido drásticamente, por el descenso de la demanda de mano de obra en nuestro mercado de trabajo. La contracción de la actividad económica ha provocado un cambio de orientación de la política migratoria del estado español, cuya mayor preocupación hasta ahora constituía la normalización de un voluminoso flujo de inmigrantes en continua progresión. Así, la nueva política migratoria española resulta disuasoria para los que están fuera, claramente integradora de los que están dentro, abierta a la repatriación de los que así lo deseen y —experimentalmente- descentralizada en todos sus aspectos.

PAlabras ClaVE: inmigración; inmigración en España; inmigración y crisis económica en España; recesión económica y migraciones laborales.

\section{AbSTRACT}

Preceded by a significant flow of immigrants in the last two decades of the twentieth century, the increase of the foreign residents in Spain since 2000 has been extraordi- 
nary. In 1999 the number of foreign residents in Spain was 750,000 (1.86\% of the total population). Ten years later, foreigners living in Spain are more than 5.5 million (12\% of the total population). But after 2007, flows of inmigrant workers have been modified as a result of the global economic downturn. The numbers of new immigrant workers in Spain have been dramatically reduced by the decline in demand in our labor market. The economic recession caused a shift in immigration policy in Spain, which to this point focused on amnesties of large influxes of immigrants in continuous progression. The new Spanish immigration policy is deterrent to those outside, clearly inclusive of those within, open to the repatriation of those who so desire, and, experimentally, fully decentralized.

KEY WORDS: immigration; immigration in Spain; immigration in Spain and economic crisis; economic recession and labor migration.

\section{RÉSUMÉ}

Limpact de la crise économique internationale dans la politique d'immigration espagnole. Précédé par un flux important d'immigrants au cours des deux dernières décennies du xxe siècle, l'augmentation de la population étrangère résidant en Espagne depuis 2000 a été remarquable. En 1999, le nombre de résidents étrangers en Espagne a été 750.000 (1,86\% de la population totale). Dix ans plus tard, les étrangers vivant en Espagne sont plus de 5,5 millions (12\% de la population totale). Mais après 2007, les flux de travailleurs immigrés ont été modifiés à la suite de la récession économique mondiale. Larrivée de travailleurs immigrés en Espagne ont été considérablement réduits par la baisse de la demande de main-d'œuvre dans notre marché du travail. La contraction de l'activité économique a entraîné un changement dans la politique d'immigration de l'État espagnol, qui s'occupait principalement de la régularisation d'un afflux important d'immigrants en progression continue. Maintenant, la politique d'immigration espagnole est dissuasive sur ceux à l'extérieur, clairement intégrative de ceux à l'intérieur, ouverte au rapatriement de ceux qui le souhaitent et, expérimentalement, décentralisée dans tous ses aspects.

MoTS CLÉS: immigration; immigration en Espagne; immigration en Espagne et crise économique; récession économique et migrations de travail. 